\title{
The impact of the subtropical South Atlantic SST on South American precipitation
}

\author{
A. S. Taschetto ${ }^{1}$ and I. Wainer ${ }^{2}$ \\ ${ }^{1}$ Climate Change Research Centre (CCRC), University of New South Wales, UNSW, 2052, Sydney, NSW, Australia \\ ${ }^{2}$ Department of Physical Oceanography, Institute of Oceanography, University of São Paulo, Praça do Oceanográfico, 191 - \\ 05508-120, São Paulo, SP, Brazil
}

Received: 13 December 2007 - Revised: 15 September 2008 - Accepted: 10 October 2008 - Published: 10 November 2008

\begin{abstract}
The Community Climate Model (CCM3) from the National Center for Atmospheric Research (NCAR) is used to investigate the effect of the South Atlantic sea surface temperature (SST) anomalies on interannual to decadal variability of South American precipitation. Two ensembles composed of multidecadal simulations forced with monthly SST data from the Hadley Centre for the period 1949 to 2001 are analysed.
\end{abstract}

A statistical treatment based on signal-to-noise ratio and Empirical Orthogonal Functions (EOF) is applied to the ensembles in order to reduce the internal variability among the integrations. The ensemble treatment shows a spatial and temporal dependence of reproducibility. High degree of reproducibility is found in the tropics while the extratropics is apparently less reproducible. Austral autumn (MAM) and spring (SON) precipitation appears to be more reproducible over the South America-South Atlantic region than the summer (DJF) and winter (JJA) rainfall. While the Inter-tropical Convergence Zone (ITCZ) region is dominated by external variance, the South Atlantic Convergence Zone (SACZ) over South America is predominantly determined by internal variance, which makes it a difficult phenomenon to predict. Alternatively, the SACZ over western South Atlantic appears to be more sensitive to the subtropical SST anomalies than over the continent.

An attempt is made to separate the atmospheric response forced by the South Atlantic SST anomalies from that associated with the El Niño - Southern Oscillation (ENSO). Results show that both the South Atlantic and Pacific SSTs modulate the intensity and position of the SACZ during DJF. Particularly, the subtropical South Atlantic SSTs are more important than ENSO in determining the position of the SACZ over the southeast Brazilian coast during DJF. On the other hand, the ENSO signal seems to influence the intensity of the SACZ not only in DJF but especially its oceanic

Correspondence to: A. S. Taschetto

(a.taschetto@unsw.edu.au) branch during MAM. Both local and remote influences, however, are confounded by the large internal variance in the region. During MAM and JJA, the South Atlantic SST anomalies affect the magnitude and the meridional displacement of the ITCZ. In JJA, the ENSO has relatively little influence on the interannual variability of the simulated rainfall. During SON, however, the ENSO seems to counteract the effect of the subtropical South Atlantic SST variations on convection over South America.

Keywords. Meteorology and atmospheric dynamics (General circulation; Ocean-atmosphere interactions; Precipitation)

\section{Introduction}

A number of severe weather and climate-related events in South America in recent years have led to disasters of devastating consequences thus arousing the need to understand them. An excess of precipitation may lead to floods, which can bring diseases to the local population. On the other hand, the lack of rainfall may cause severe droughts and economical loss, as precipitation in South America plays an essential role in determining the hydroelectric power production in many parts of the continent. For instance, a serious energy crisis occurred in summer 2001 due to the rainfall deficit, particularly in southeastern, northeastern and central Brazil (Drumond and Ambrizzi, 2005). Since energy production, agriculture and many other socio-economic activities in South America have been adapted to rainfall patterns, it is essential to improve our knowledge of rainfall variability in the region.

South American rainfall is characterized by a marked annual cycle with a dominant rainy season during the austral summer (DJF) when the monsoon system prevails over the continent. The most common feature of the South American monsoon regime is the South Atlantic Convergence

Published by Copernicus Publications on behalf of the European Geosciences Union. 
Zone (SACZ). The SACZ is a convective band that extends northwest-southeast from the Amazon Basin to the subtropical South Atlantic Ocean (Kodama, 1992, 1993). This convective zone, identifiable by its cloudiness and low irradiance, is frequently configured in DJF.

Some studies have reported the importance of local factors in the SACZ onset, like the South America continentality and its topography (Satyamurty and Rao, 1988; Gandu and Geisler, 1991; Lenters and Cook, 1995), the convection over the Amazon Basin (Rocha and Gandu, 1996) and the persistence of frontal systems in the subtropics (Carvalho et al., 2002). Gandu and Geisler (1991) found that the South American topography blocks the low-level inflow from the equatorial Pacific, and leads to the development of a steady, northerly jet along the eastern flank of the Andes that is fed by the strengthened northeasterly winds from the tropical Atlantic. Using a simple general circulation model with the presence of South America, Lenters and Cook (1995) highlighted the importance of the continentality and the consequent generation of the thermal low on the SACZ onset. The development of the low pressure system over Chaco region strengthens the gradient between the continental low and the South Atlantic subtropical high leading to southward lowlevel winds (Lenters and Cook, 1995, 1999). These summer pressure systems in association with the advection of moisture from northeasterly trade winds and the poleward flow at low levels produce enhanced precipitation in the Amazon, central and southeastern Brazil, thus configuring the SACZ.

Herdies et al. (2002) found that the weakening of the northwesterly low level jet along the Andes Mountains can be associated with the SACZ events. Moisture is transported through the low level jet from the Amazon to the subtropical latitudes of South America, favouring rainfall over the La Plata Basin, northern Argentina, Paraguay and southern Brazil. Therefore, the stronger low level jet can be associated with the absence or weakening of the SACZ, while the presence of westerly winds are related to strong convective activity over the SACZ region (Herdies et al., 2002).

Remote factors are also important for the variability of the South American monsoon system. In intraseasonal timescales, the Madden-Julian Oscillation (MJO) has shown to be the main mode of the atmospheric variability within 30-60 days (Madden and Julian, 1994) affecting the monsoon regime in South America (Casarin and Kousky, 1986; Grimm and Silva Dias, 1995; Nogués-Paegle and Mo, 1997; Liebmann et al., 1999, 2004; Paegle et al., 2000; Cunningham and Cavalcanti, 2006). More recently, de Souza and Ambrizzi (2006) showed that the MJO is the main atmospheric mechanism affecting the intraseasonal variations of the SACZ and the ITCZ, which in turn modulate the rainfall in eastern Amazon and Northeast Brazil.

Carvalho et al. (2004) suggested that different regions of the SACZ can be modulated by distinct physical mechanisms. The authors divided the SACZ according to the regions with maximum convective activity and minimum sub- seasonal variance (i.e. Amazon region), and maximum subseasonal variance (i.e. coast and ocean). They suggest that the MJO modulates intense SACZ events on intraseasonal timescales. On interannual timescales, they have shown that the frequency of the coastal and oceanic SACZ events depends on the phase of the El Niño-Southern Oscillation (ENSO).

The relationship between the Pacific Ocean and rainfall over South America through atmospheric teleconnection has been reported before in previous studies (e.g. Kalnay et al., 1986; Garreaud and Battisti, 1999; Mo, 2000; Cavalcanti, 2000; Paegle and Mo, 2002). In general, the anomalous warm water associated with ENSO events induces changes in the Hadley and Walker circulations, generating Rossby wave trains that affect the South American rainfall (Grimm, 2003). Karoly (1989) found a wave train extending from the Pacific Ocean to South America, which has been identified as the Pacific-South American pattern (PSA), a typical response to ENSO. Kalnay et al. (1986) reported a relationship between the enhanced SACZ and the eastward displacement of the South Pacific Convergence Zone (SPCZ). Grimm and Silva Dias (1995) found that a southeastward shift of the SPCZ from its climatological position during El Niño events tends to intensify the SACZ convection. Drumond and Ambrizzi (2005) speculated that an intensified convective activity over the SPCZ and a westward displacement of its mean position may be connected to the inhibition of the SACZ convection, suggesting an opposite atmospheric response due to anomalous heat sources in different locations in the tropical Pacific. On decadal timescales, Andreoli and Kayano (2005) provide strong evidence that the Pacific Decadal Oscillation (PDO) impacts precipitation over South America.

In terms of the influence from the local South Atlantic SST on precipitation over the continent, many studies have focused on the tropical latitudes (Hastenrath and Heller, 1977; Moura and Shukla, 1981; Nobre and Shukla, 1996; Chang et al., 2000; Saravanan and Chang, 2000). Whether or not the local subtropical SSTs impact the SACZ is still a remaining question. Diaz et al. (1998) and Barros et al. (2000) reported a correlation between warm SST anomalies in the South Atlantic and the South American rainfall. In contrast, Figueroa et al. (1995) argue that warm SSTs in the southwestern South Atlantic have no effect on the SACZ because they are located north of the band position. Robertson and Mechoso (2000) found observational evidences that a northsouth dipole pattern in SST anomalies over the southwest Atlantic are associated with an anomalous cyclonic (anticyclonic) circulation and intensified (weakened) SACZ. The authors, however, suggest that the local SSTs are a response to atmospheric anomalies. Conversely, Barreiro et al. (2002) used a suite of AGCM simulations to show that the oceanic branch of the SACZ is influenced by a dipole pattern of SST anomalies over the southwest South Atlantic. Robertson et al. (2003) showed that cold SST anomalies in the subtropical South Atlantic tend to damp the SACZ and extend it 
poleward. They also presented some evidence of a feedback between the SSTs and the SACZ. Chaves and Nobre (2004) identified the presence of a cloud/shortwave - SST negative feedback between the atmosphere and the ocean over the southwest Atlantic. They suggest that the cold SSTs underlying the oceanic part of the SACZ are a response to atmospheric forcing, which in turn weakens the convective band. To date, there is no consistent consensus regarding the influence of the subtropical South Atlantic SSTs on precipitation.

Most of the above studies have investigated the influence of SST anomalies on South American rainfall focusing on DJF, due to the extensive continental area with a dominant austral summer rainy season. However, there are some regions where the largest precipitation is generated by different mechanisms than the SACZ. For instance, during austral autumn, the Northeast Brazil is affected by the southward migration of the ITCZ that determines the rainy season in the region (Hastenrath, 1991). During the winter season, the South American precipitation is influenced by frontal systems, which are one of the most common synoptic events over the continent (Kousky, 1979; Kousky and Ferreira, 1981). These systems flow northward into the continent, causing intense drop in temperature and strong meridional winds. In some cases, the cold air incursions can reach all the way into the Amazon Basin (Kousky, 1979, 1980). Kousky and Ferreira (1981) have reported the penetration of frontal systems into the Amazon and their role in modulating the rainfall in the region.

In this study we examine the variability of the South American precipitation using multidecadal ensemble integrations from an atmospheric general circulation model (AGCM) forced with SST anomalies in the global oceans and in the subtropical South Atlantic. Most of the studies addressing the South Atlantic effects on South American climate focus on the tropical SSTs. It is a common sense that the atmospheric response to SST anomalies is more detectable in the tropics than in the extratropics. Nevertheless, it does not mean that the subtropical/extratropical SSTs have no effect onto atmosphere. Indeed, Haarsma et al. (2003) indicate that the subtropical South Atlantic SST anomalies do have a significant impact on the equatorial dynamics of the atmosphere. For this reason, we forced the AGCM with prescribed SSTs in subtropical South Atlantic.

Apart from the idealized SST experiment, this study is also original in terms of the seasonality. The previous studies on subtropical South Atlantic SST tend to limit their results in the austral summer impact, when the South American rainfall is higher in most of the continent due to the presence of the SACZ. As an ensemble of multidecadal simulations is used here, we will analyse the interannual to decadal variability in precipitation not only during DJF but also in all the other seasons. While the interannual variability of summer rainfall is the largest, we show that the low-frequency modes of variability during the other seasons are not negligible.
This paper is organized as follows. Section 2 briefly describes the model and the numerical experiments. Section 3 compares the simulated rainfall with observations, as well as between the numerical experiments. A statistical treatment applied to the ensembles is described in Sect. 4. In Sect. 5 we investigate the precipitation response to the subtropical South Atlantic SSTs in the ensemble mean. In Sect. 6, an attempt is made to separate the ENSO influence from that of the South Atlantic SST on South American rainfall. Section 7 shows the response due to the local subtropical South Atlantic SST anomalies without the ENSO signal. Finally, the last section discusses our results, summarizing the major findings of this work.

\section{The AGCM and the numerical experiments}

We used the Community Climate Model (CCM3) AGCM from the National Center from Atmospheric Research (NCAR). The CCM3 (Acker et al., 1996) has a T42 spectral truncation in the horizontal (approximately 2.8 lat $\times 2.8$ lon degrees) and 18 vertical levels. Land surface processes in the CCM3 are represented by the Land Surface Model LSM (Bonan, 1998). Improvements from the latest version to the CCM3 are described in Kiehl et al. (1998).

Five-member ensembles were produced with slightly different initial atmospheric conditions in order to represent the internal variability. According to Shukla (1993) the tropical atmospheric patterns are strongly determined by the underlying SSTs, especially when a large-scale seasonal simulation is run for a long period. Shukla (1998) showed that two integrations with different initial atmospheric conditions respond very similarly to the tropical Pacific SSTs. Thus, the author suggests that a small ensemble size is sufficient to reproduce internal atmospheric dynamic processes. In our case, as we focus on subtropical SSTs, we used five integrations for each ensemble. Previous studies such as Chang et al. (2000), Saravanan and Chang (2000) and Barreiro et al. (2002) have had good results for precipitation and atmospheric circulation with a relatively small ensemble size performed with the NCAR CCM3 model forced with SSTs in the tropical Atlantic and South Atlantic Ocean, involving similar decades as used in this work. In addition, this ensemble size is in agreement with the estimate of Taschetto and England (2008).

Two experiments were generated with the CCM3. The first experiment (EXP1) was carried out with monthly varying SSTs in the global oceans. The EXP1 is used here as a control run. The second experiment (EXP2) was forced with SSTs varying only in the South Atlantic Ocean between $20^{\circ} \mathrm{S}-60^{\circ} \mathrm{S}$, in order to obtain the local contribution of the subtropical latitudes. Climatological SST values were assigned elsewhere in the global oceans.

The data set used to force the CCM3 was the global seaice and SST analyses (HadISST1) from the Hadley Centre. The monthly mean fields of SST and sea-ice concentration 
cover the globe in $1^{\circ}$ latitude $\times 1^{\circ}$ longitude grid, which was interpolated to the CCM3 grid. The HadISST1 has been shown to be an improvement upon the GISST data set. A detailed description of this dataset can be found in Rayner et al. (2003). The ensembles were integrated from September 1949 to October 2001. In order to eliminate possible effects of the initial conditions as well as to fix 12-months in a year, the first few and last months of the integrations were discarded, with the period of January 1950 to December 2000 remaining. Thus, this study is based on 51 years of monthly mean output of two five-member multidecadal ensembles. The time series were split into the austral seasons: December, January and February (DJF) for summer; March, April and May (MAM) for autumn; June, July and August (JJA) for winter; and, September, October and November (SON) for spring.

\section{The simulations and the observational data}

In order to verify the model performance in simulating precipitation over the South America-South Atlantic region, we compared the ensemble mean from EXP1 with the observed rainfall data compiled by Xie and Arkin (1997). The Xie and Arkin (1997) data set, also known as the CPC Merged Analysis of Precipitation (CMAP), was produced by merging several data sources, including rain gauge observations, estimates inferred from a variety of satellite observations, and the NCEP/NCAR reanalysis. The CMAP was constructed on a $2.5^{\circ}$ latitude-longitude grid for the period January 1979 to December 2001. Thus, 23 -yr monthly averaged precipitation data were used in the comparison. To be consistent with the observed climatology, the simulated precipitation was averaged over the same period as the CMAP.

Figure 1 exhibits the observed and simulated seasonal mean rainfall. In general, precipitation is overestimated in South America, while the seasonal rainfall variations are well captured by the model. It shows an intensification of rainfall over the continent in austral summer (Fig. 1b) and its reduction during the winter months (Fig. 1f). As described in the introduction, the elongated band of rainfall during DJF over the continent indicates the presence of the SACZ, thus defining the rainy season in Southeast Brazil. The suppression of precipitation throughout the year over the eastern side of the oceans is well simulated in the model. It is also observed an increase in autumn rainfall near the equator (Fig. 1d), off the northeast Brazilian coast. The latter indicates the southward migration of the ITCZ. Nevertheless, simulated precipitation over tropical Atlantic, Amazon Basin, and especially along the Andes Mountains is overestimated, which is a known bias in the CCM3 (Boville and Gent, 1998; Hack et al., 1998).

Essentially, we can conclude that the simulated precipitation is in reasonably agreement with observations, representing the main features in South American rainfall, e.g. SACZ and ITCZ. In addition to that, since we are interested in the variability of precipitation, it is more important that the model capture well the seasonal variations rather than the magnitude itself. It is shown that the CCM3 can also reproduce fairly well the seasonal variations. Saravanan (1998) has shown that the CCM3 provides a good simulation of the atmospheric low-frequency variability. The performance of the model is also tested in the next section in terms of the variability of precipitation.

The difference of the seasonal mean rainfall between EXP1 and EXP2 is depicted in Fig. 2. The relative agreement of the climatological DJF and JJA rainfall between the ensemble means can be attested by the low values in Fig. $2 \mathrm{a}$ and c, respectively. The main differences, however, are seen during MAM and SON. During austral autumn (Fig. 2b), EXP2 simulates an increased mean rainfall over South America and weakened precipitation over tropical Atlantic off the Northeast Brazil coastline. On the other hand, reduced rainfall is seen over the continent for EXP2 during SON (Fig. 2d). The surprising agreement between the EXP1 and EXP2 summer rainfall not necessarily suggests that the South American monsoon can be reproduced by solely the subtropical South Atlantic SST anomalies, but instead it indicates that the SACZ is likely to be internally dynamic driven. Conversely, the mean MAM rainfall associated with the ITCZ seems to have a strong contribution from the underlying tropical South Atlantic SST. The increase of the mean precipitation during MAM and decrease during SON across South America simulated in EXP2 may be due to the absence of other forcing sources, such as the tropical Atlantic and Pacific SSTs. These issues are evaluated in the next section.

\section{The treatment of ensemble}

The tropical atmosphere is generally sensitive to changes in SSTs. Tropical variability on interannual timescales is dominated by SST forcing, such as the ENSO phenomena. On the other hand, the subtropical/extratropical variations are dominated by internal atmospheric variability, which are difficult to predict on seasonal timescales, especially regarding precipitation.

In a small set of integrations, the ensemble mean is composed by both signal and noise. The noise is commonly referred to as internal variance or spread among ensemble members, while the signal is the external variance. When the noise is larger than the signal, atmospheric variations are usually not potentially predictable. According to Yang et al. (1998), it does not mean that the SSTs cannot impact the extratropical atmosphere, but only that the amplitude of the forcing response is smaller than the noise. In order to reduce the internal variability and increase the reproducibility in the ensembles, the authors decompose the integrations using Empirical Orthogonal Functions (EOF) and reconstruct them with the most reproducible modes. Basically, they can isolate the externally forced response even in regions where 


\section{XIE-ARKIN}
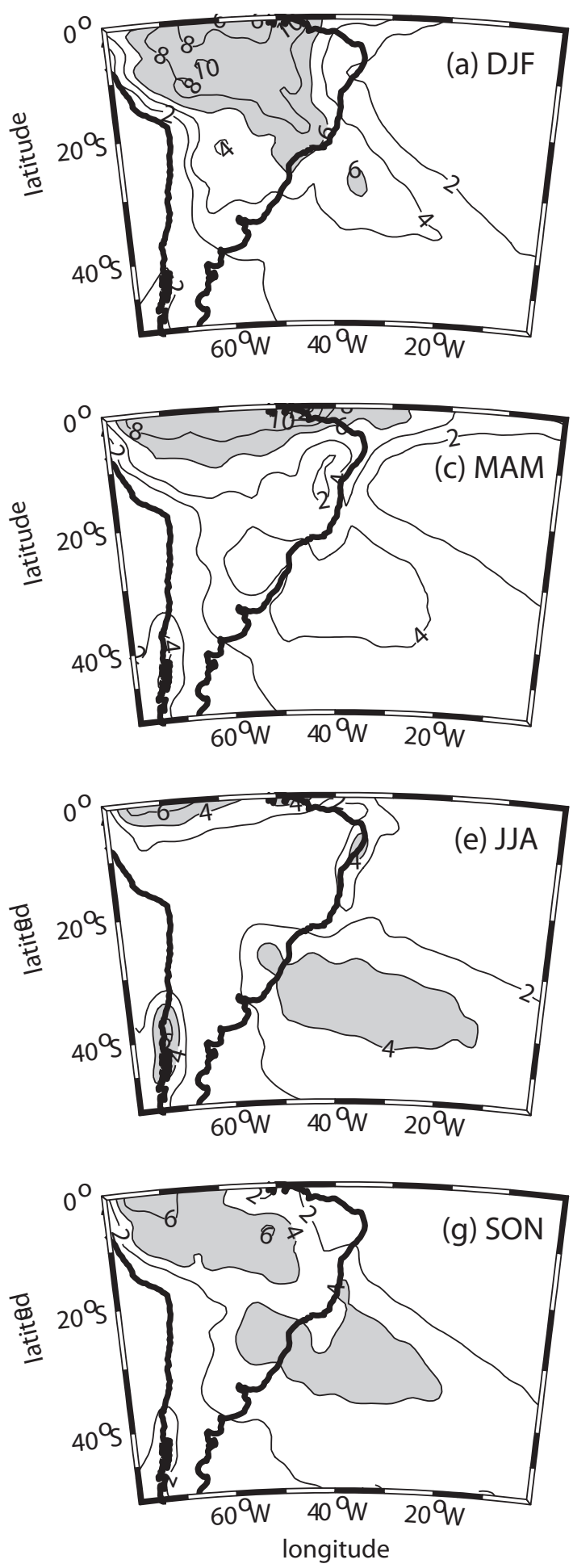

CCM3
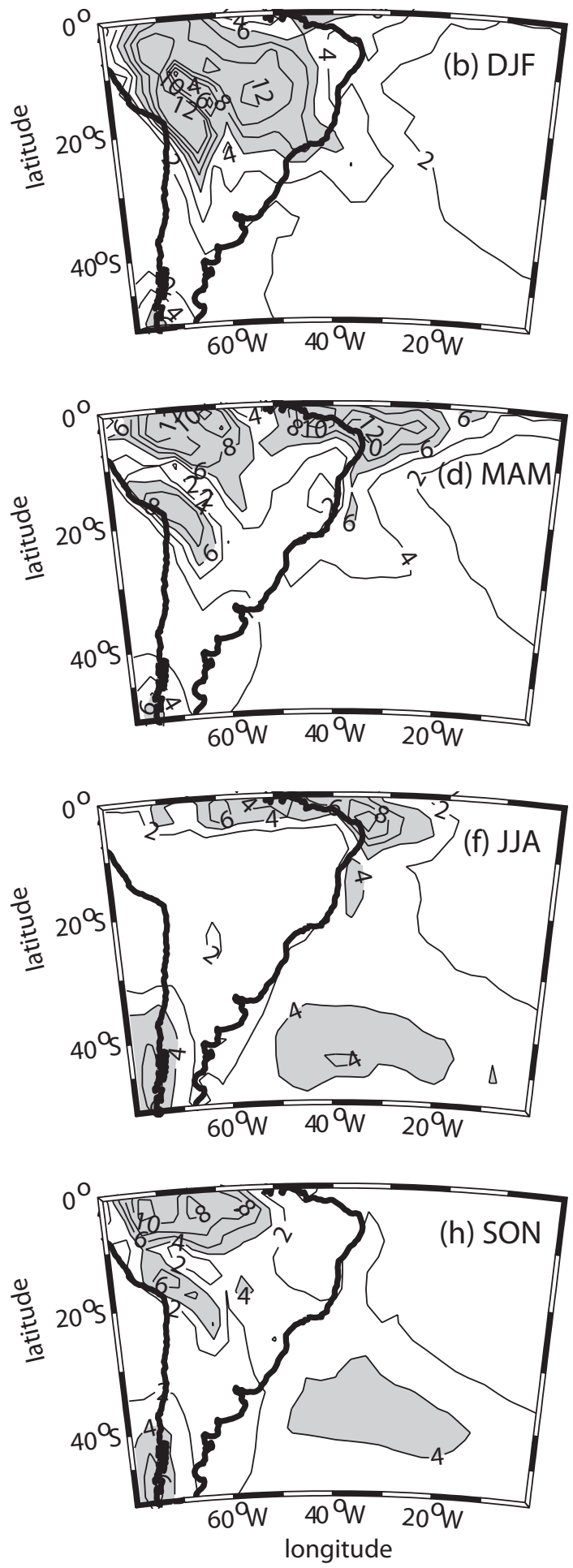

Fig. 1. Seasonal mean precipitation comparison: Xie and Arkin (1997) in the left column and EXP1 ensemble mean in the right column. (a-b) DJF, (c-d) MAM, (e-f) JJA and (g-h) SON. Contour interval is $2 \mathrm{~mm} \mathrm{day}^{-1}$. Rainfall greater than $6 \mathrm{~mm} \mathrm{day}^{-1}$ in DJF and MAM and $4 \mathrm{~mm} \mathrm{day}^{-1}$ in JJA and SON are shaded to facilitate the comparison. 
(a) DJF

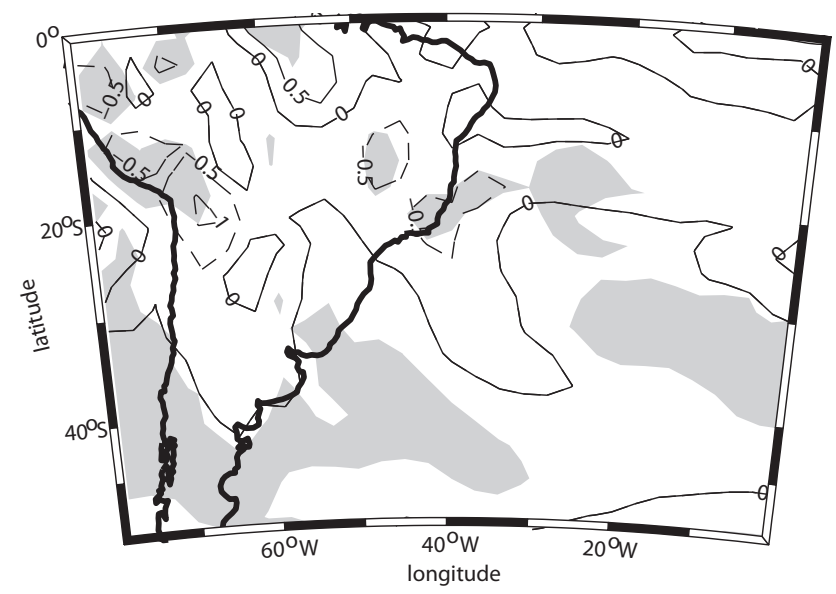

(c) JJA

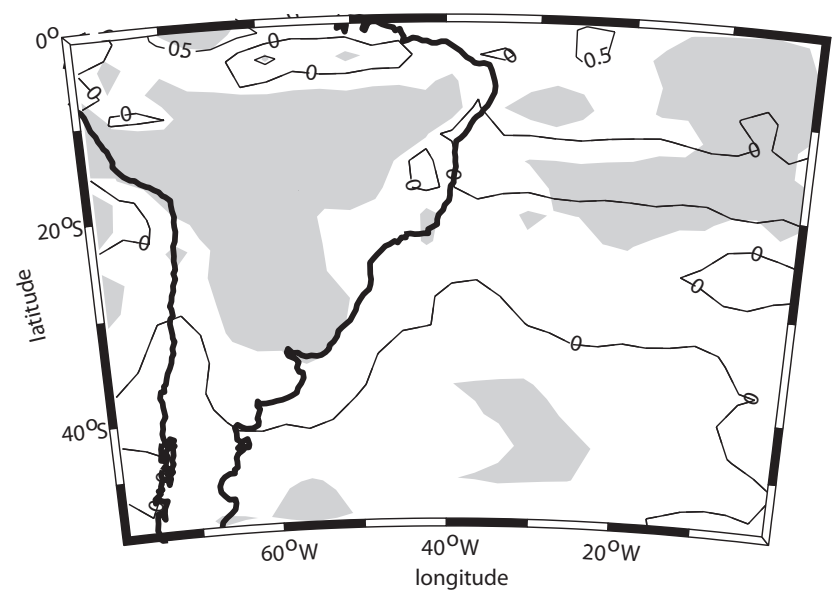

(b) MAM

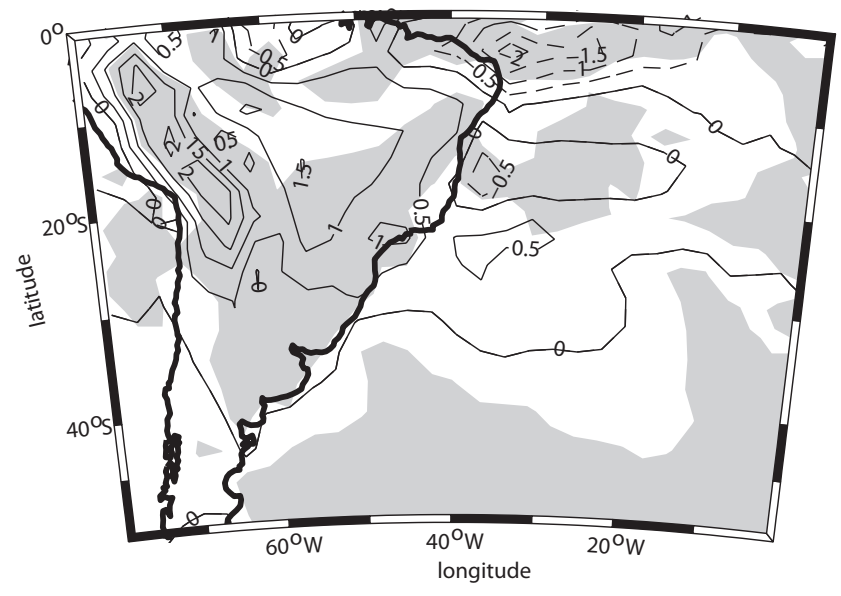

(d) SON

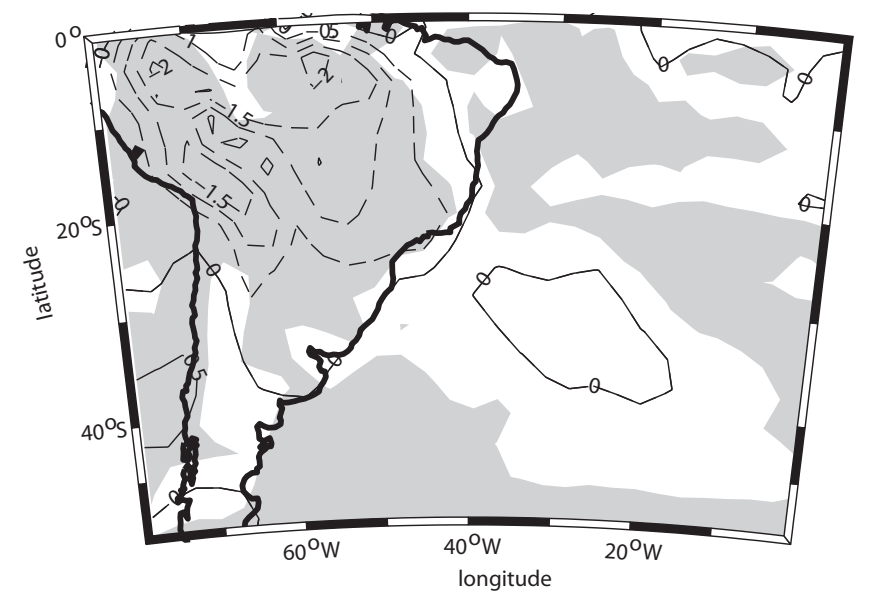

Fig. 2. Difference of the seasonal mean precipitation between EXP1 and EXP2. Positive (negative) rainfall indicates an overestimate (underestimate) from EXP2 to EXP1. Contour interval is $0.5 \mathrm{~mm} \mathrm{day}^{-1}$. Shading represents areas where EXP2 is statistically different from EXP1 at the $95 \%$ level according to a t-student test. (a) DJF, (b) MAM, (c) JJA and (d) SON.

it seems insignificant when compared to internally generated atmospheric noise.

In this study, the technique of Yang et al. (1998) is employed in order to examine and increase the reproducibility (commonly referred to as potential predictability to SSTs) of simulated precipitation in the CCM3. This first evaluation is very important to verify the model performance, before speculating on the mechanisms by which the SST anomalies impact the climate. Only the main results of the statistical treatment are shown here, a detailed discussion can be found in Taschetto and Wainer (2008).

The reproducibility index is based on the signal-to-noise ratio, as defined in Yang et al. (1998):

$R=1-\frac{\sigma_{I}}{\sigma_{T}}$ where $\sigma_{I}$ is the internal variance or a measure of the ensemble spread and $\sigma_{T}$ is the total variance, which satisfies the relationship $\sigma_{T}=\sigma_{E}+\sigma_{I}$, with $\sigma_{E}$ as the external variance.

The internal variance $\sigma_{I}$ is computed by taking into account the difference among the integrations in relation to the ensemble mean at each month, thus giving an estimate of the internal variability of the atmosphere. The external variability $\sigma_{E}$ is the ensemble mean variance. If the external variability dominates the internal variability, the seasonal atmospheric variations are potentially predictable. In other words, if the reproducibility $R$ is close to 1 , the internal variance $\sigma_{I}$ does not dominate the total variance $\sigma_{T}$. In this case, the ensemble is considered to be highly reproducible and the seasonal variations are determined by the external forcing (i.e. SSTs). 
Although the technique is applied to both EXP1 and EXP2, only the latter is shown here, as the main purpose of this study is to examine the effect of the subtropical South Atlantic SSTs on rainfall. Notwithstanding, the results for EXP1 are fairly similar to those for EXP2, except for general larger magnitudes of the reproducibility index. This is expected due to the different domains of SST forcing in the numerical experiments.

The spatial distribution of reproducibility from the original ensemble for EXP2 is depicted on the left column of Fig. 3. Generally, the reproducibility is larger over the tropics than over the subtropical/extratropical latitudes. Another important feature in Fig. 3 is the seasonal dependence of reproducibility. On average, it is larger in MAM (Fig. 3b) and SON (Fig. 3d) than in DJF (Fig. 3a) and JJA (Fig. 3c). The transient seasons (Fig. 3b and d) show a higher reproducibility over South America and Africa continents, while the extremes seasons (Fig. 3a and c) reveal larger reproducibility in the tropical ocean. The seasonal differences in the reproducibility (Fig. 3, left column) are related to a larger scattering among the ensemble members during austral summer and winter than in the transient seasons.

The low reproducibility over South America during DJF (Fig. 3a) compromises the prediction of the SACZ events. At the same time, the spatial distribution of reproducibility suggests that the signal due to the SST forcing is stronger in the ITCZ region than in the SACZ. Apparently, the rainfall reproducibility in DJF over most of Brazil is lower than 0.3 (Fig. 3a), indicating that the internal variance accounts for approximately $70 \%$ of the total variance (Taschetto and Wainer, 2008). This reveals that the SACZ region over South America is dominated by internal variance, which explains the difficulty in predicting this phenomenon. Barreiro et al. (2002) also find that the SACZ region is dominated by internal variability. Conversely, the internal variance in the ITCZ region during DJF accounts for less than $30 \%$. In fact, the role of the SSTs on the ITCZ variations has been already reported by several authors (Moura and Shukla, 1981; Nobre and Shukla, 1996; Servain, 1991; Chang et al., 2000).

There are a few areas in the southeastern South Atlantic that are more reproducible than in the southwest region, especially during MAM and SON (Fig. 3b and d). This indicates that the SSTs play an important role in the oceanic region south off Africa in autumn and spring.

It is worthwhile to point out that the seasonal variation of reproducibility also depends on the variable studied as well as the model, since there are differences on physical parameterizations and initial conditions used to generate the ensembles. Based on another AGCM, Yang et al. (1998) showed that the reproducibility is larger in JJA and lower in DJF for $850 \mathrm{hPa}$ temperature anomaly (T850) and $300 \mathrm{hPa}$ geopotential height anomaly. The potential predictability index is especially low in DJF T850 over South America (Yang et al.'s Fig. 11). Using the European Centre for Medium-Range Weather Forecasts (ECMWF) model, Brankovic et al. (1994) found a preference in $200 \mathrm{mb}$ zonal wind and $500 \mathrm{mb}$ height for boreal spring season (MAM) and attributed this to the small internal spread of the ensemble.

Following Yang et al. (1998), we decomposed the ensemble in EOF modes and reconstructed it with the first few reproducible modes. The truncation level used for the reconstruction was defined by using three different methods: the North et al. (1982) error, the white noise null-hypothesis by Monte Carlo algorithm and the potential predictability index defined in Yang et al. (1998). Whilst the North et al. (1982) error plus the Monte Carlo test define the lower threshold for the truncation level, the Yang et al. (1998's) predictability index was used as the superior limit. The truncation level was chosen to be the number of EOF modes that represents $80 \%$ of the maximum potential predictability index. Thus the ensemble was reconstructed using the first 8 EOFs for DJF, 10 for MAM, 7 for JJA, and 9 for SON. Details about the EOF reconstruction can be seen in Taschetto and Wainer (2008).

After the reconstruction of ensemble using the selected level of truncation, the reproducibility increased substantially in many areas, as shown in the right column of Fig. 3. The increase in reproducibility over extratropical South Atlantic is evident during austral autumn and spring (Fig. 3f and $\mathrm{h}$, respectively). It is also noticeable the rise of reproducible areas during DJF (Fig. 3e) and JJA (Fig. 3g), despite smaller amplitudes. This growth in the reproducibility is due to the reduction in internal variance $\sigma_{I}$ after the reconstruction of the ensemble. In other words, the reconstructed ensemble contains much less spread among the members than the original ensemble. Consequently, the externally forced signal $\sigma_{E}$ becomes competitive in the total variance $\sigma_{T}$ and results a higher reproducibility (see Eq. 1).

Although austral summer also had its noise reduced in the reconstructed ensemble (Fig. 3e), it is still significant in central South America. On the other hand, reproducibility over the oceanic branch of the SACZ has increased significantly. The internal variance is reduced up to $50 \%$ off the Southeast Brazilian coast. This suggests that the subtropical South Atlantic SSTs have more impact on the oceanic SACZ than on its continental part. Investigating this relationship is important for understanding the SACZ predictability.

\section{Responses on Experiment 2 (EXP2)}

Since the focus of this paper is the response in precipitation due to the local forcing, we investigate the EXP2, which was forced with monthly SST anomalies varying only in the subtropical South Atlantic Ocean. The two leading modes of variability were examined through Rotated EOF (REOF) analysis applied to the monthly time series for each season. The REOF is used here to eliminate any orthogonality imposed by the EOF method. Eigenvectors were rotated using the "varimax" criterion. The number of EOF modes retained in the rotation was chosen by the North et al. (1982)'s 
(a) D.JF

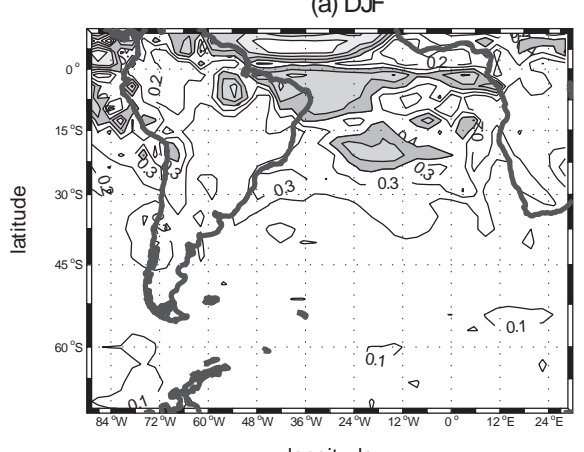

longitude

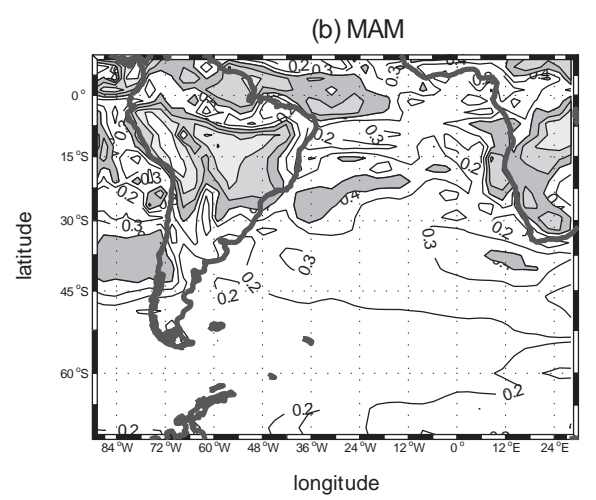

(c) UA

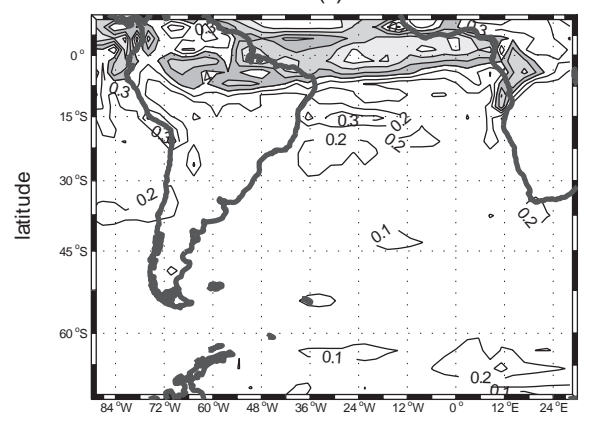

longitude

(d) SON

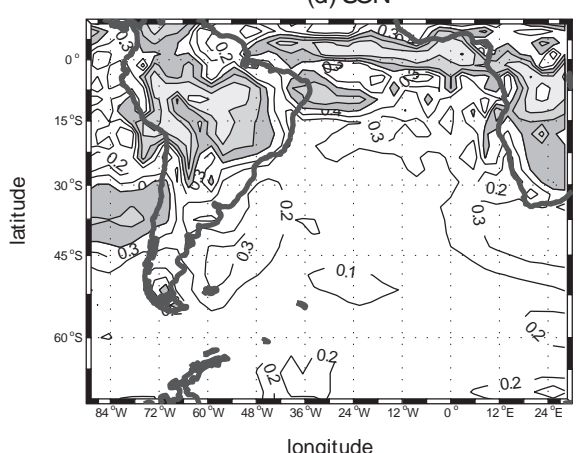

(e) D.JF

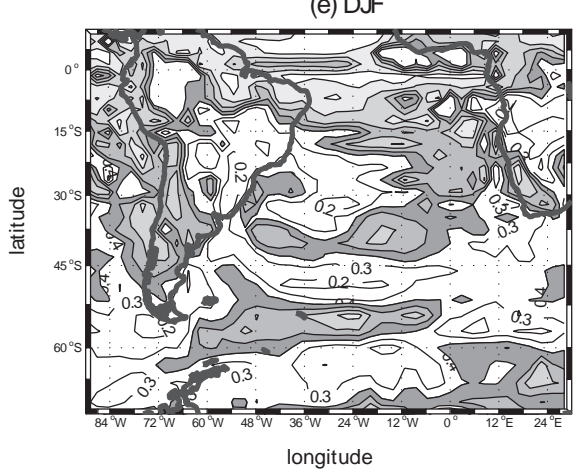

(f) MAM

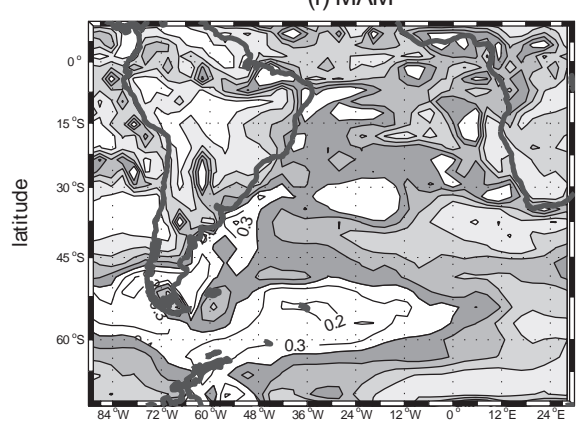

longitude

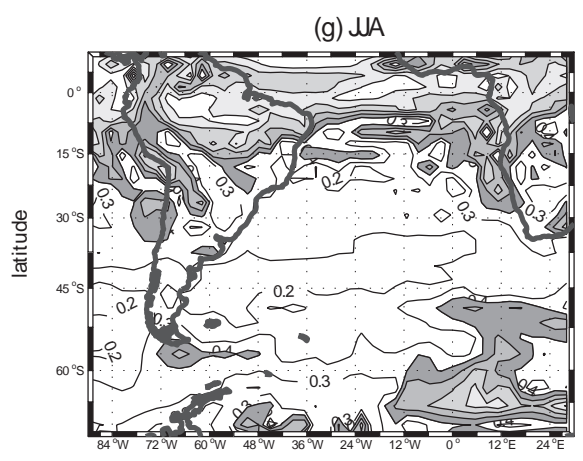

longitude

(h) SON

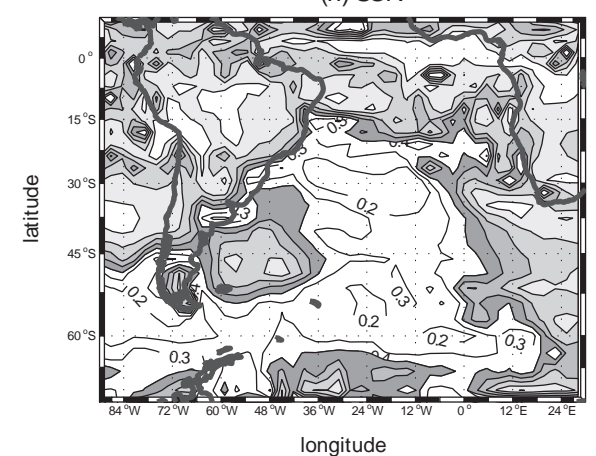

Fig. 3. Spatial distribution of reproducibility for the original (a-d, left column) and reconstructed ensemble (e-h, right column) in the South Atlantic region. Shaded areas indicate reproducibility greater than 0.4. Contour interval is 0.1. Adapted from Taschetto and Wainer (2008). 


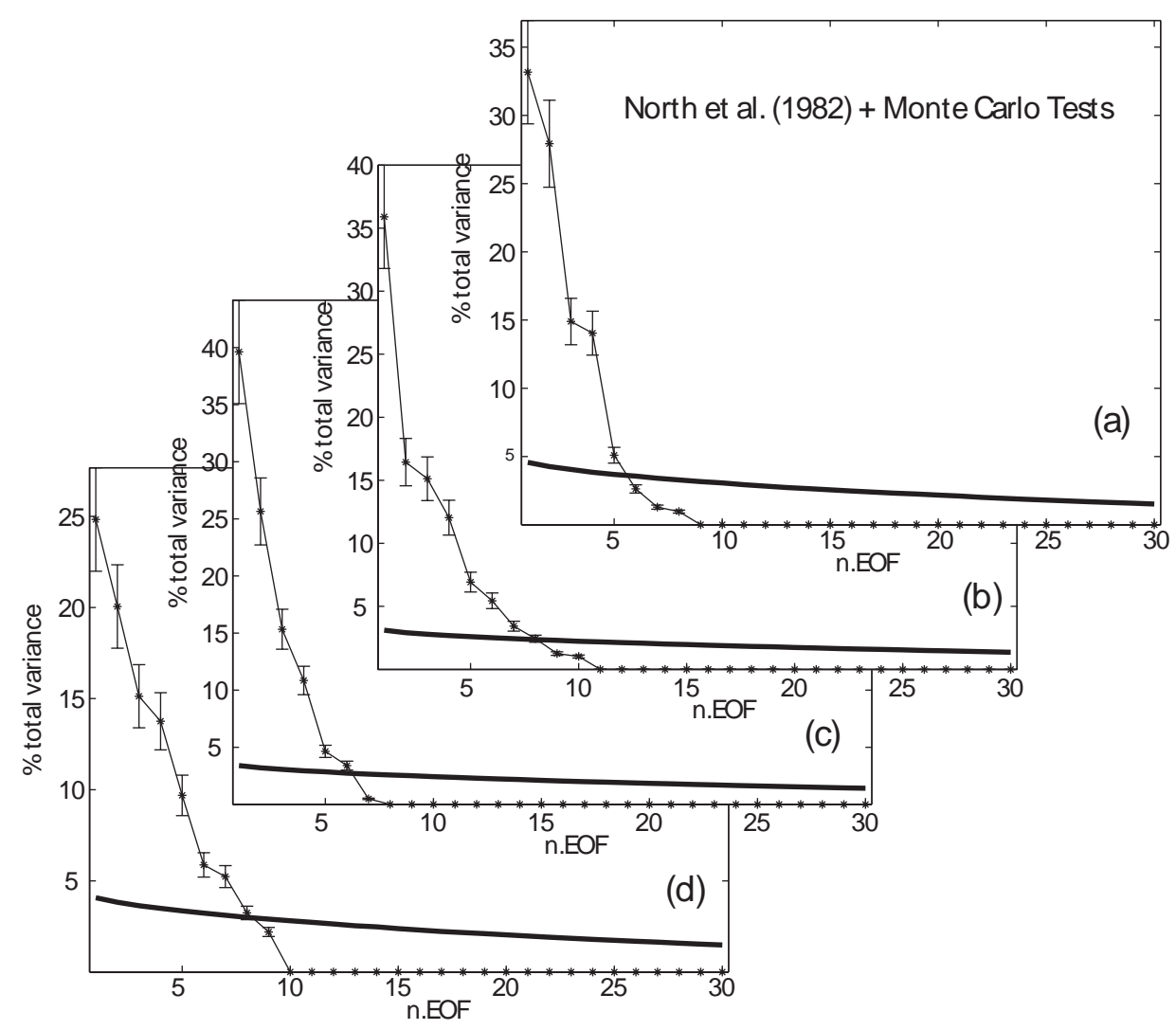

Fig. 4. Percentage of explained variance of the EOF modes for (a) DJF, (b) MAM, (c) JJA and (d) SON. Error bars estimated by North et al. (1982)'s rule of thumb. Thick line indicates the Monte Carlo test.

rule of thumb criteria and Monte Carlo test. Significances of the EOF modes estimated by North et al. (1982) are based on comparing the separation among the neighbouring eigenvalues with its sampling error. The Monte Carlo procedure distinguishes the explained variance obtained from the EOF analysis by testing it against a white noise null-hypothesis. Figure 4 depicts the explained variances with these two tests. The number of EOF used for the rotation was determined by the eigenvalue whose inferior error bar from North's rule does not intercept the Monte Carlo threshold. Thus, the number of EOF modes retained for the rotation was 5 for DJF, 7 for MAM, 6 for JJA and 6 for SON.

Figure 5 shows the first REOF mode of precipitation for all seasons. It accounts for $31 \pm 4 \%, 18 \pm 2 \%, 21 \pm 2 \%$ and $20 \pm 2 \%$ of the total explained variance for DJF, MAM, JJA and SON, respectively.

In DJF (Fig. 5a), the first mode of variability reveals an elongated band of negative eigenvectors extending from central Brazil to the southwestern South Atlantic. Simultaneously, positive eigenvectors are seen over Southern Brazil. This configuration is associated with the reduction/intensification of the SACZ and the decrease/increase of rainfall in Southern Brazil and vice versa, varying accordingly to the expansion coefficient time series. In its positive phase, the configuration shows enhanced rainfall in Southern Brazil simultaneously with the suppression of precipitation over Central and Southeast Brazil. This pattern is consistent with findings of Casarin and Kousky (1986), Nogués-Paegle and Mo (1997), Robertson and Mechoso (2000), Barreiro et al. (2002) and Herdies et al. (2002). The latter authors suggest that the negative phase of this see-saw pattern in summer rainfall variability is related to moisture convergence in the Amazon and Southeast Brazil, concomitantly with the weakening of the moisture flux to Southern Brazil, thus modulating convective outbreaks in those regions. According to Herdies et al. (2002), the positive phase of this mode of variability is observed with the strengthening of the low level jet along eastern Andes Mountains that brings moist air to $\mathrm{La}$ Plata Basin, favouring rainfall over the region. At the same time, the authors describe the absence of the SACZ event. This mode of variability is associated with an interannual oscillation of 4 and 2.5 -yr period.

During the austral autumn (Fig. 5b) the leading REOF mode depicts a centre of negative eigenvectors at $23^{\circ} \mathrm{S}-$ $37^{\circ} \mathrm{W}$ and positive values over central South America. Also, some variability is found over the tropical South Atlantic. This pattern is associated with a low frequency oscillation of approximately $7 \mathrm{yr}$ period. It indicates an increase/decrease 

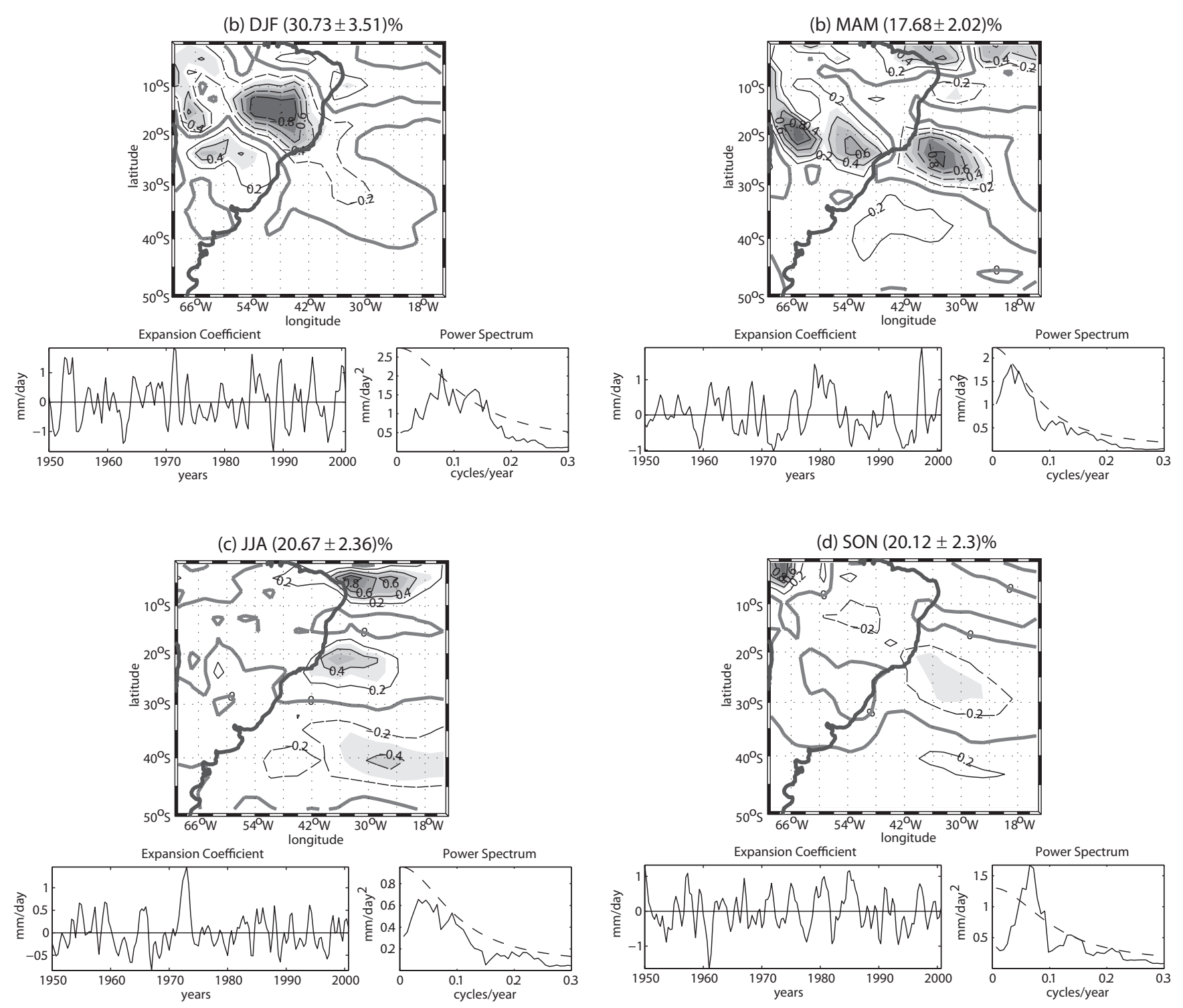

Fig. 5. First mode of REOF for simulated precipitation from EXP2. Shaded areas represent eigenvector magnitudes higher than $|0.3|$. Time series of expansion coefficients $\left(\mathrm{mm} \mathrm{day}^{-1}\right)$ and the associated power spectrum are located in the panel below. The power spectrum is calculated via multitaper method. Frequencies above the dashed line are significant at the $95 \%$ level relative to a red noise background spectrum. (a) DJF, (b) MAM, (c) JJA and (d) SON.

of rainfall over the continent together with the suppression/enhancement of precipitation over the oceanic branch of the SACZ.

In winter season (Fig. 5c) the first REOF mode reveals higher variability over the ocean than the continent. This winter pattern is larger off the Northeast Brazilian coast. It suggests the intensification/weakening of rainfall related to the ITCZ.

Figure 5d exhibits negative values north of approximately $35^{\circ} \mathrm{S}$ in the region of study and positive in south of this latitude. A centre of negative values located around $25^{\circ} \mathrm{S}$, $32^{\circ} \mathrm{W}$ is associated with dry conditions over southwestern
South Atlantic, suggesting the modulation of the oceanic branch of the SACZ. Also, positive eigenvectors are located in the northwest Amazon Basin, representing enhanced convective activity in northwestern South America. This mode is associated with a variability of 5-yr period.

Figure 6 depicts the second leading mode of the REOF for all seasons. This mode explains the following percentage of the total variance: $20 \pm 2 \%$ in DJF, $16 \pm 2 \%$ in MAM, $20 \pm 2 \%$ in JJA and $16 \pm 2 \%$ in SON. Thus, the first two EOF modes account for approximately $51 \%, 34 \%, 41 \%$ and $36 \%$ of the total variance for austral summer, autumn, winter and spring, respectively. Interesting to note that the cumulated explained 

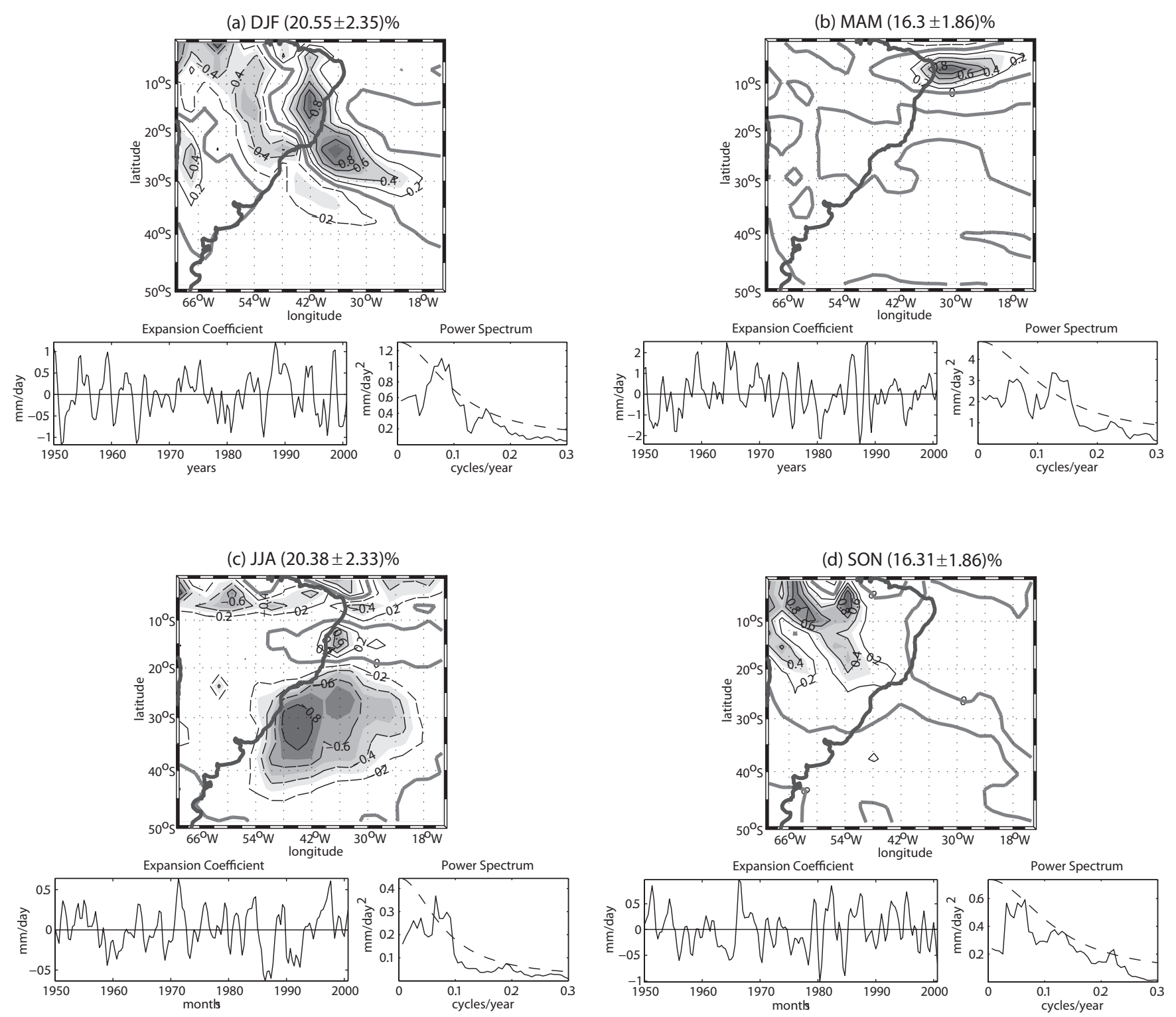

Fig. 6. Second mode of REOF for simulated precipitation from EXP2. Shaded areas represent eigenvector magnitudes higher than $|0.3|$. Time series of expansion coefficients $\left(\mathrm{mm} \mathrm{day}^{-1}\right)$ and the associated power spectrum are located in the panel below. The power spectrum is calculated via multitaper method. Frequencies above the dashed line are significant at the $95 \%$ level relative to a red noise background spectrum. (a) DJF, (b) MAM, (c) JJA and (d) SON.

variance by the dominant modes of variability is largest during DJF, which motivated the amount of studies mentioned previously in the introduction. However, the leading EOF modes for the other seasons are not negligible and also reveal significant fractions of the total variance, thus motivating this study.

The second mode of variability in DJF (Fig. 6a) shows a dipole pattern across the Brazilian coast. This feature indicates the meridional shift of the SACZ mean position. Therefore, the first two modes of summer precipitation variability are associated with the intensity and the location of the SACZ phenomenon in summer. This second REOF mode is associated with a period of 3.5 to 4.5 years of variability.

Austral autumn (Fig. 6b) reveals positive eigenvectors over the extreme northeast region in Brazil, extending eastward to tropical Atlantic. It is clearly associated with the intensity of the ITCZ. The southward migration of the ITCZ determines the rainy season in the extreme northeastern Brazil (Hastenrath and Heller, 1977). This pattern presents an interannual variability with a 2 to 2.5 -yr period.

Figure $6 c$ exhibits large variability in the tropical latitudes of the studied region. In addition, a well defined centre of 
precipitation is seen at the subtropical South Atlantic, suggesting the influence of the local SSTs on the rainfall variability in a period of 5 and 4-3.5 years.

The austral spring pattern (Fig. 6d) shows positive eigenvectors over the continent, suggesting the presence/absence of the convection over the Amazon Basin. The time series of expansion coefficients presents three significant peaks with a period of $5,2.5$ and 1.5 years.

The EOF analysis performed in EXP1 yields relatively similar patterns as in EXP2, unless for stronger magnitudes (figure not shown). However, it is interesting to highlight some differences in the DJF and MAM patterns. The leading mode of DJF variability for EXP1 reveals negative eingenvectors extending further southeastern over the western South Atlantic than those in Fig. 5a. In addition, the first mode of MAM rainfall variability shows larger eigenvectors over the equatorial Atlantic Ocean rather than in the subtropics as in Fig. 5b. These differences suggest the importance of the subtropical South Atlantic SST anomalies in modulating the summer and autumn rainfall variability over the region.

\section{The remote response}

It is well recognised that the El Niño-Southern Oscillation (ENSO) is one of the largest climatic events affecting the globe (Trenberth and Caron, 2000). The anomalous warm SST associated with ENSO involves approximately one third of the tropics. Because of this, ENSO leads to changes in atmospheric circulation, impacting several regions around the world (Trenberth, 1991). In South America, ENSO plays an important role in rainfall variability. As our primarily interest is the investigation of the precipitation due to the South Atlantic SSTs, the influence of ENSO has to be factored out from the results shown in the previous section. Note that, even though the EXP2 was forced only with SST anomalies varying in South Atlantic, it still contains the influence from remote SSTs.

The correlation between the NINO3 Index and the precipitation over the region demonstrates the Pacific remote influence on EXP2 (Fig. 7). In general, the correlation coefficients are low for EXP2. This is an expected result as this experiment was forced with SST anomalies only in the subtropical South Atlantic. When the same analysis is carried out with EXP1, a much stronger correlation pattern appears (figure not shown), particularly over the tropical latitudes where El Niño events tend to dry the Northeast Brazil via the shift of the Walker circulation.

Despite the low correlation coefficients for EXP2 (Fig. 7), there are some areas with significant values, especially during summer. Therefore, it is an important step to eliminate the ENSO remote signal. In order to do this, the simulated precipitation from EXP2 was firstly regressed onto the NINO3 Index. This procedure enhances the precipitation variability associated with the ENSO signal in EXP2.
Then, this component was subtracted from the EXP2 ensemble mean, thus removing the ENSO remote influence.

The regression pattern for EXP2 is shown in Fig. 8. It is worthwhile to comment that significantly stronger patterns are seen for EXP1 (figure not shown), indicating that the SST design of EXP2 by itself is efficient in reducing considerable the ENSO influence on rainfall. Nevertheless, the most expressive ENSO influence on EXP2 appears to be in austral summer and autumn (Fig. 8a and b, respectively). These two seasons reveal similar signal over the southwest South Atlantic. Positive regression coefficients can be seen around $25^{\circ} \mathrm{S}-33^{\circ} \mathrm{W}$, and negative are located at about $18^{\circ} \mathrm{S}-36^{\circ} \mathrm{W}$ for both seasons. This indicates that ENSO tends to enhance the convection over the SACZ, particularly over its oceanic branch, during DJF and MAM. Reduced rainfall is seen over southern Brazil during summer (Fig. 8a). During winter and spring (Fig. 8c-d), the regression pattern does not show great effect from ENSO. Slightly positive values are exhibited over the tropical Atlantic near equator in winter (Fig. 8c) and over northeastern South America in spring (Fig. 8d).

Comparisons of the regression patterns between the numerical experiments reveal markedly negative values over northern and northeastern South America for EXP1 during all seasons, and slightly positive values over the Central and South Brazil particularly in MAM (figure not shown). This pattern is not well developed in EXP2 (Fig. 8) because the experiment design does not contain SST anomalies in the tropical Pacific. The rainfall increase in the Southern Brazil, simultaneously with the suppression of precipitation in the northern part of the continent is a common feature during El Niño years (e.g. Kousky et al., 1984; Ropelewski and Halpert, 1987, 1989; Grimm et al., 2000; Grimm, 2003). During El Niño events, the Walker circulation shifts due to the eastward displacement of warm waters in the Pacific Ocean. The displacement of the atmospheric heat source overlaying the warmest water results in ascending air in the eastern tropical Pacific, which in turn descends over Northeast Brazil, suppressing convection and rainfall in that region. Moreover, during Pacific warm events, the enhanced subtropical jet acts like a barrier, inhibiting frontal systems to go northward over the continent, and confining them to the south. Paegle and Mo (2002) suggested that the ENSOrelated PSA wave train increases the pressure gradient between the Chaco low and the Atlantic subtropical high, contributing to an increased supply of moisture and enhanced precipitation over eastern Brazil.

\section{The local response}

After subtracting the ENSO-related regression pattern from EXP2, the REOF analysis was used again in order to look for differences. Figure 9 shows the leading mode of variability for EXP2 without the ENSO signal. It now accounts for $24 \pm 3 \%, 19 \pm 2 \%, 22 \pm 2 \%$ and $22 \pm 2 \%$ of the total variance 
(a) DJF

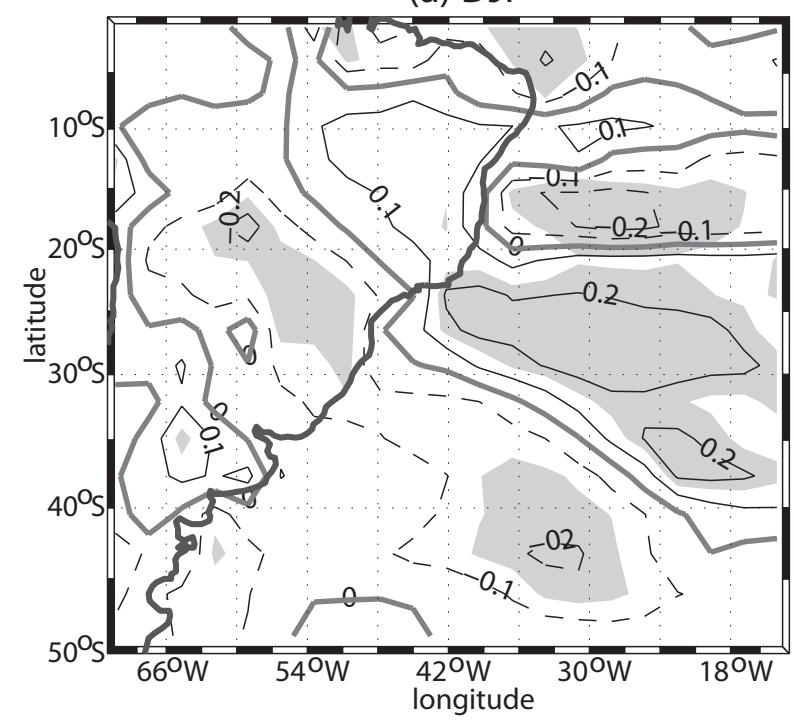

(c) JJA

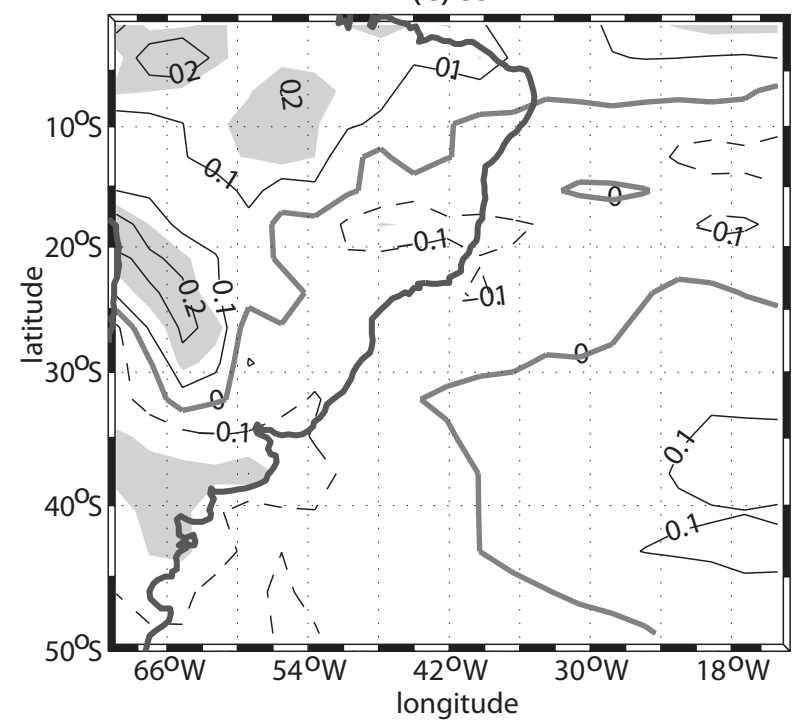

(b) MAM

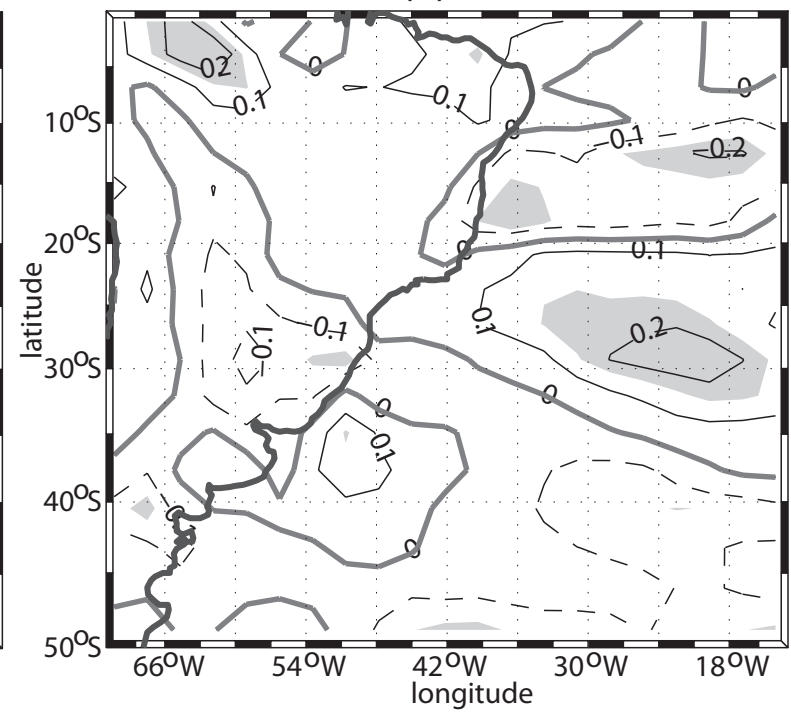

(d) SON

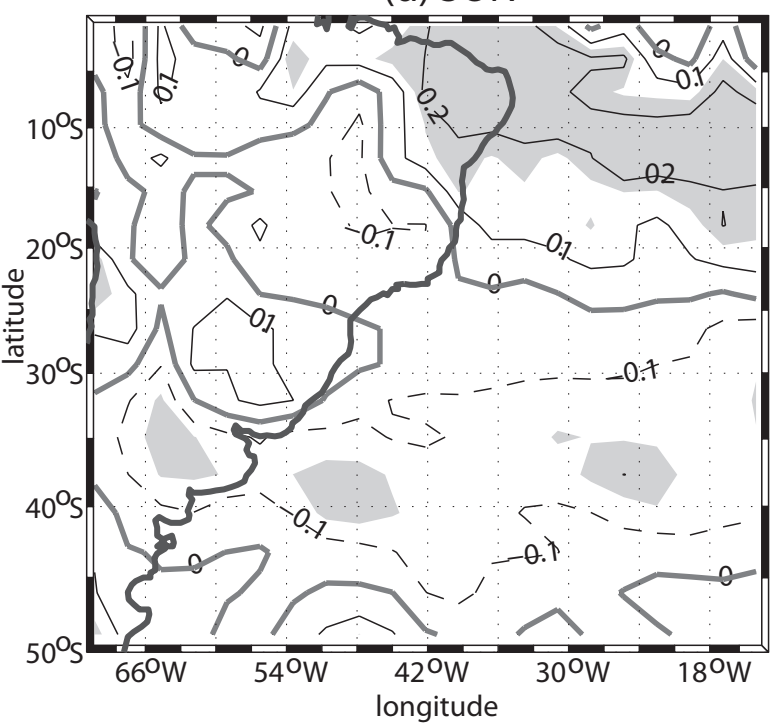

Fig. 7. Spatial distribution of correlation between the Niño3 Index and the simulated precipitation anomalies from EXP2. (a) DJF, (b) MAM, (c) JJA and (d) SON. Correlation coefficients larger than 0.16 are significant at a $95 \%$ of confidence level.

in DJF, MAM, JJA and SON, respectively. It is worth noting a slight decrease in the explained variance in DJF, and an increase in the variance in all the other seasons.

In DJF, the leading mode of EOF (Fig. 9a) reveals a very similar pattern compared to Fig. 5a. This suggests that the local SSTs play an important role in modulating the SACZ variability. This result corroborates the findings of Robertson et al. (2003) who reported the importance of the South Atlantic SST anomalies to the SACZ variability. Nevertheless, the pattern is now associated with smaller explained variance and a considerable different power spectrum, which suggests that the ENSO has an effect on the SACZ variability both in its coastal and oceanic parts. The comparison of the power spectrum from Figs. 5a and 9a reveals that the ENSO signal acts with a period of approximately 4 years while the South Atlantic SSTs seems to affect the SACZ variability in a higher frequency $(2.5 \mathrm{yr})$.

The following seasons reveal substantial changes in the first REOF mode after the subtraction of ENSO signal. This is especially true for the MAM mode, shown in Fig. 9b. Looking back to the REOF mode in Fig. 5b, it is clear that the ENSO signal on the oceanic branch of the SACZ was eliminated after the subtraction of the regression field. The regression analysis seen in Fig. 8b also confirms the ENSO-related signal on precipitation over the South Atlantic Ocean. Correlation between the time series of the expansion coefficient 
(a) DJF

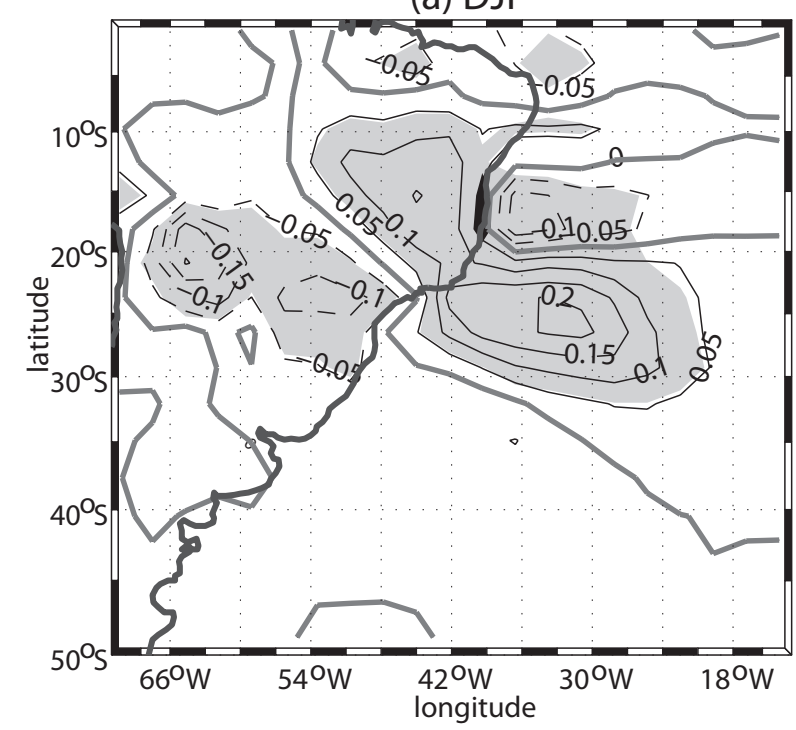

(c) JJA

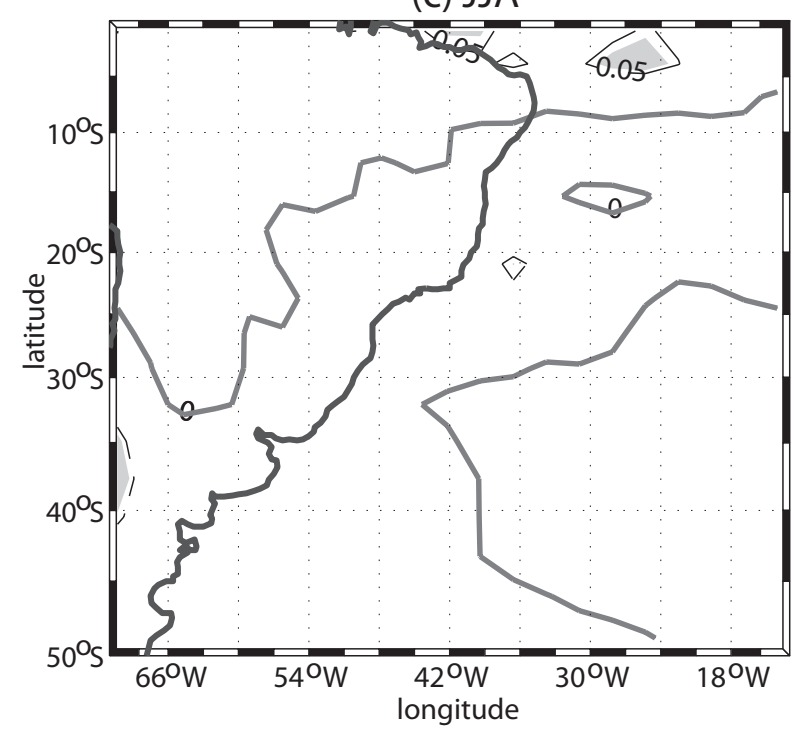

(b) MAM

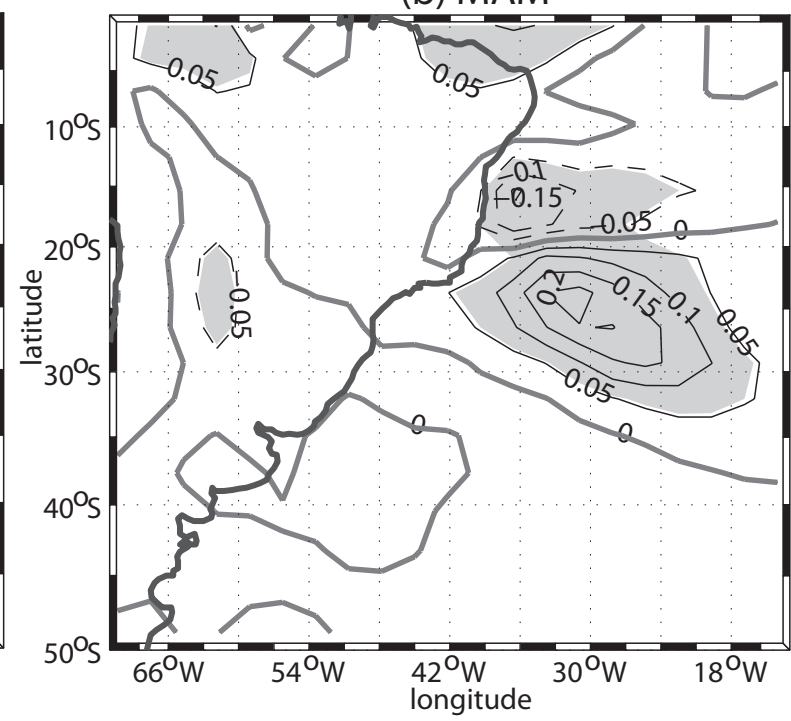

(d) SON

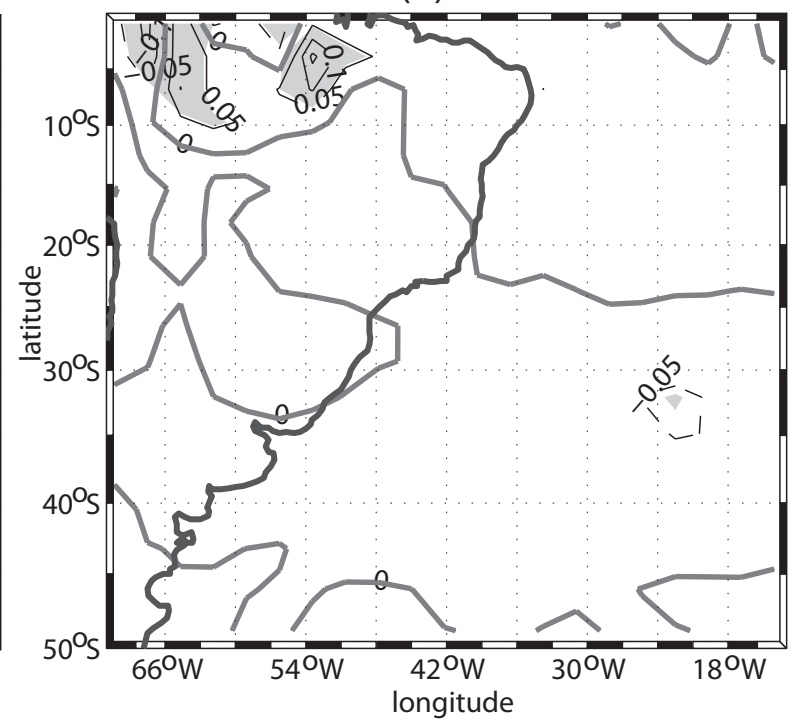

Fig. 8. Precipitation anomaly from EXP2 regressed onto the Niño3 Index. Contour interval is 0.25 . Units in mm day ${ }^{-1}$. (a) DJF, (b) MAM, (c) JJA and (d) SON.

from Fig. 5b and the NINO3 Index is significant at 95\% level. It reaches a maximum correlation of 0.42 when NINO3 Index leads the autumn principal component by 3 months. Thus we can conclude that the local SSTs affect the SACZ during summer, while the ENSO seems to influence the SACZ variability not only in summer but mostly in autumn. Generally, heat sources associated with ENSO warm events perturb the atmospheric circulation generating Rossby wave trains that can cause considerable impacts on rainfall over the studied region (Grimm, 2003). The centre of negative precipitation in Fig. 5b seems to be a response from ENSO through the PSA teleconnection pattern (Kalnay et al., 1986; Garreaud and Battisti, 1999; Mo, 2000).
Over the continent, Fig. 9b shows positive eigenvalues over the central South America and negative in the southern regions. The most important feature in the MAM pattern in Fig. 9b, however, is a dipole located over tropical South Atlantic. In a climatological sense, the southward migration of ITCZ during austral autumn is responsible for determining the rainy season in Northeast Brazil (Hastenrath and Heller, 1977). The pattern seen in Fig. 9b suggests an influence of the local SSTs, i.e. from the South Atlantic, on the meridional displacement of the ITCZ during autumn months, associated with a variability of $10-\mathrm{yr}$ period. It does not mean that the ENSO has no effect over the tropical Atlantic. Conversely, there are some studies reporting this influence, 

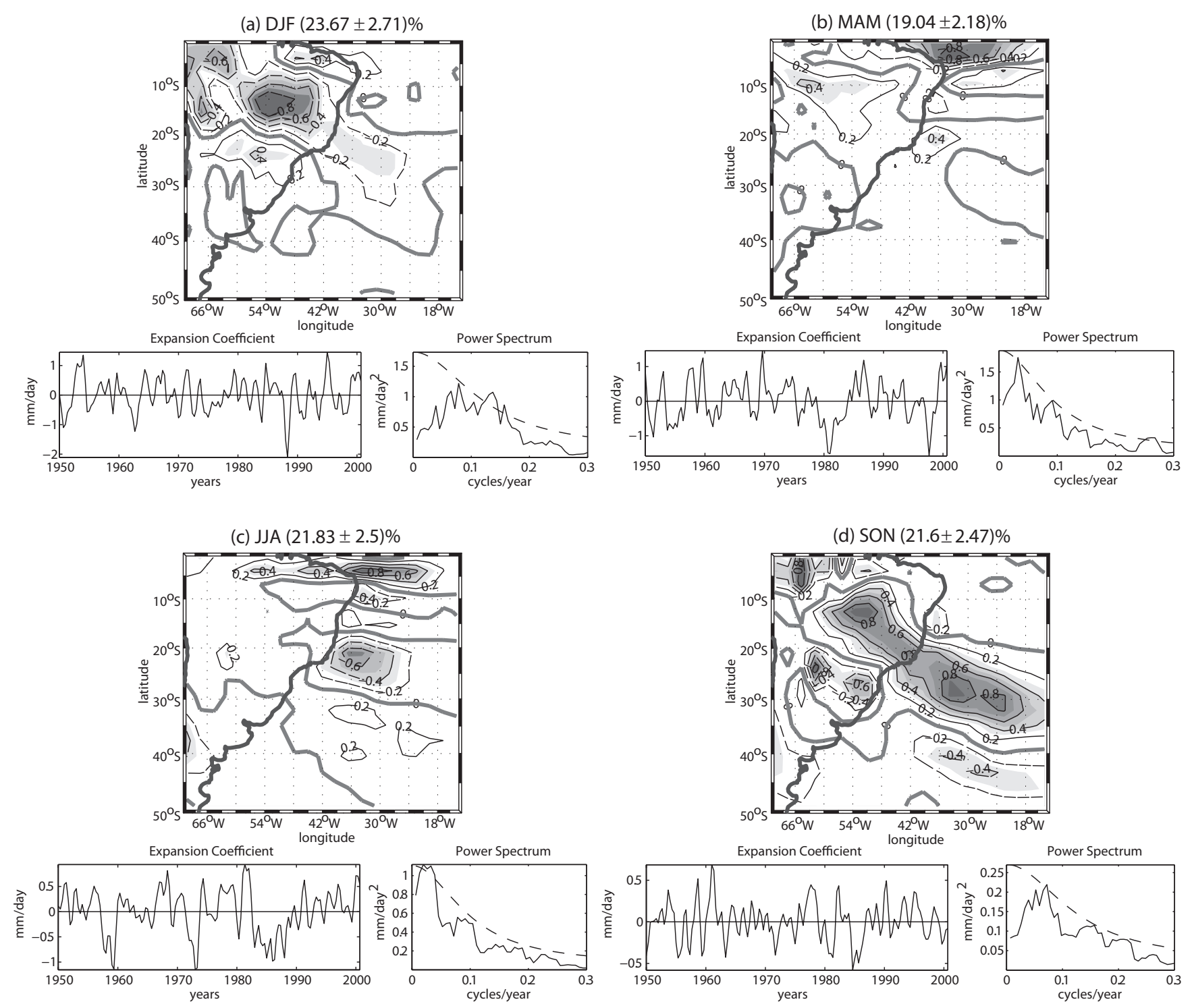

Fig. 9. First mode of REOF for simulated precipitation from EXP2 without the ENSO signal. Shaded areas represent eigenvector magnitudes higher than $|0.3|$. Time series of expansion coefficients $\left(\mathrm{mm} \mathrm{day}^{-1}\right)$ and the associated power spectrum are located in the panel below. The power spectrum is calculated via multitaper method. Frequencies above the dashed line are significant at the $95 \%$ level relative to a red noise background spectrum. (a) DJF, (b) MAM, (c) JJA and (d) SON.

such as Lau and Nath (1994), Lau (1997) and Saravanan and Chang (2000). However, the South Atlantic SSTs also seems to have a considerable influence on the tropics. According to Pezzi and Cavalcanti (2001), the Atlantic influence is comparable to, or larger than, the Pacific effects on modulating the ITCZ and precipitation in Northeast Brazil. Using numerical experiments, Haarsma et al. (2002) found that the subtropical South Atlantic SST anomalies by themselves can influence the tropical atmospheric circulation, with significant effects on the position of the ITCZ.

The JJA pattern (Fig. 9c) also shows an intense signal located over the northeast Brazilian coast elongating to the equator. This result shows that the local SSTs play an important role in determining the variability of the ITCZ precipitation not only in autumn but also in winter. In addition to that, the winter REOF mode exhibits negative eigenvalues next to the southeast Brazilian coast and positive values south of approximately $30^{\circ} \mathrm{S}$. Apart from the positive values over the ITCZ region, this mode of variability changed completely from Fig. 5c. After the subtraction of the ENSO signal, the winter leading mode shows larger amplitudes and an increase in the explained variance. Moreover, the time series of the expansion coefficients changed considerable, resulting in variability associated with a decadal period of 
(a) DJF $(22.88 \pm 2.62) \%$
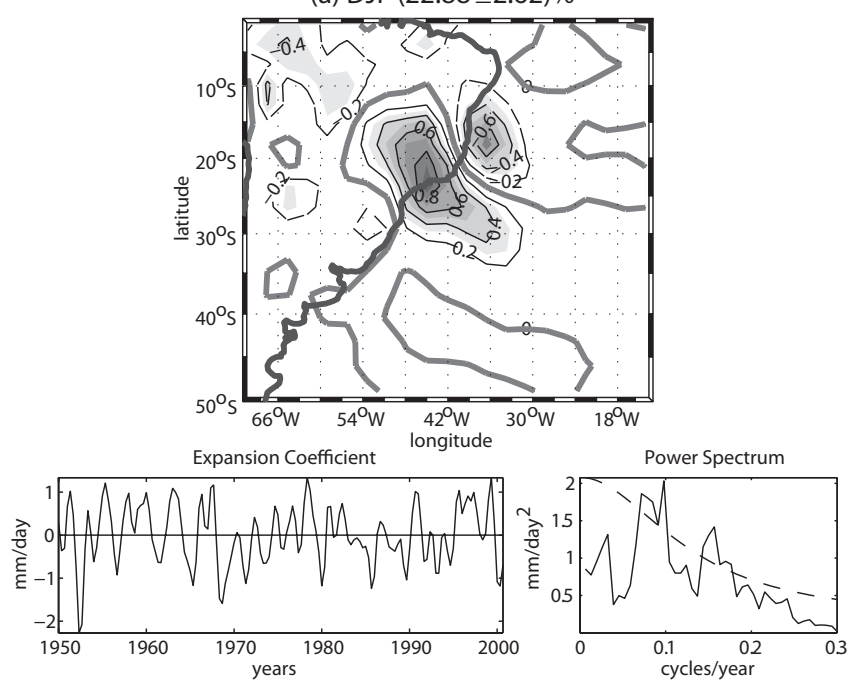

(c) JJA $(20.95 \pm 2.4) \%$

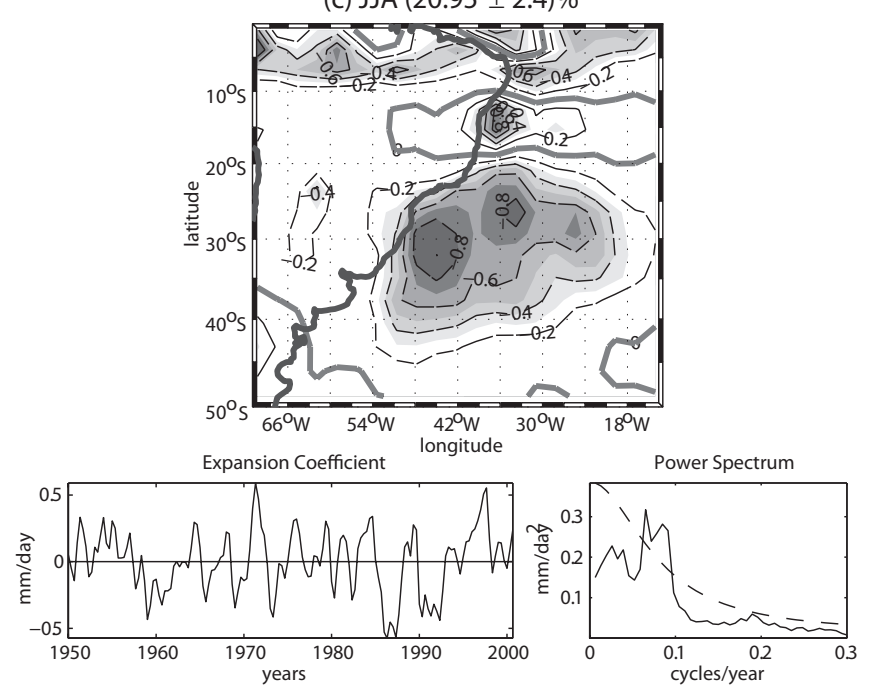

(b) MAM $(17.88 \pm 2.04) \%$
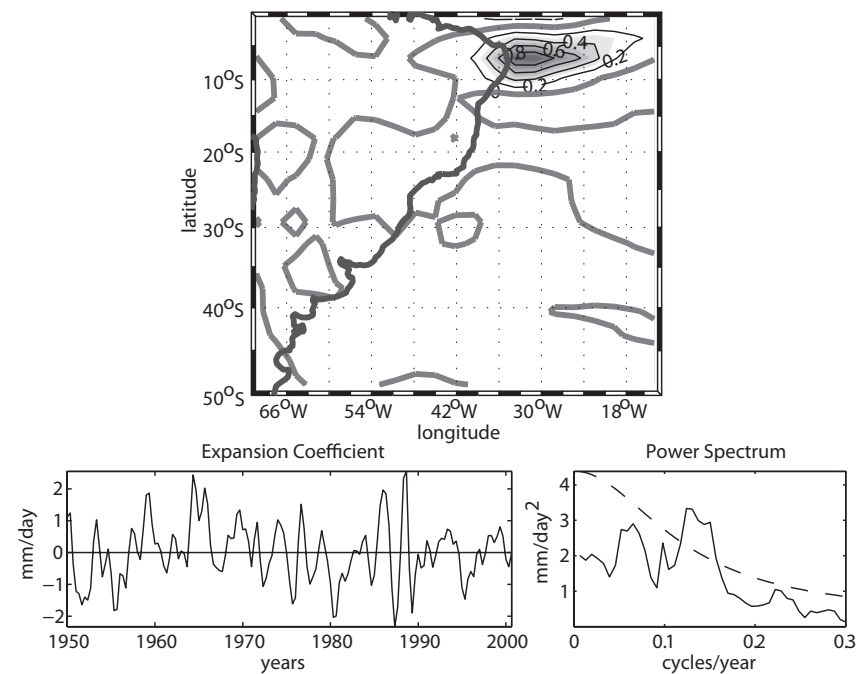

(d) SON $(16.75 \pm 1.92) \%$
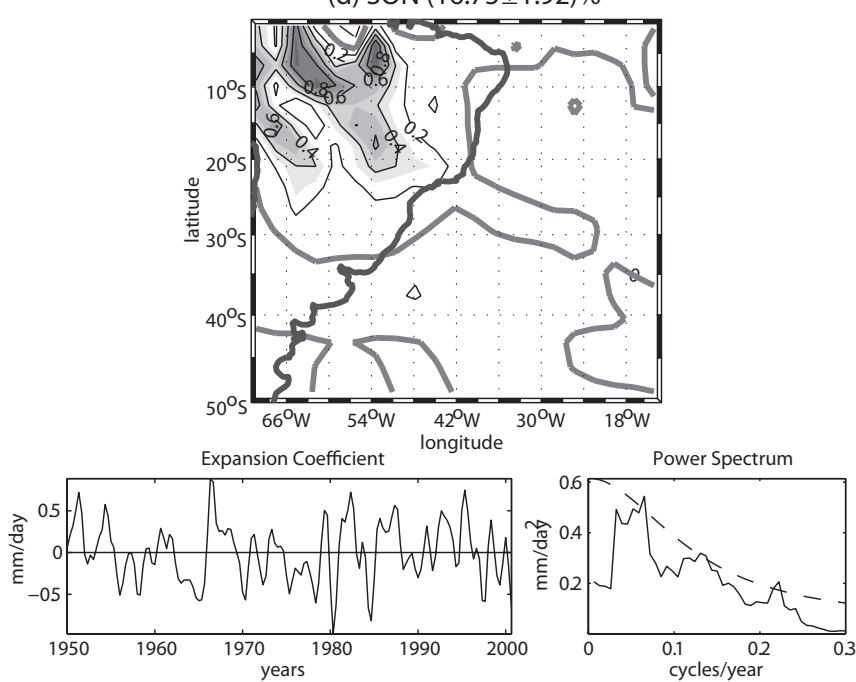

Fig. 10. Second mode of REOF for simulated precipitation from EXP2 without the ENSO signal. Shaded areas represent eigenvector magnitudes higher than $|0.3|$. Time series of expansion coefficients $\left(\mathrm{mm} \mathrm{day}^{-1}\right)$ and the associated power spectrum are located in the panel below. The power spectrum is calculated via multitaper method. Frequencies above the dashed line are significant at the $95 \%$ level relative to a red noise background spectrum. (a) DJF, (b) MAM, (c) JJA and (d) SON.

17 years. Decadal variability in the South Atlantic region has been reported by few authors. Venegas et al. (1997) found a coupled mode between the atmosphere and the ocean in South Atlantic representing a 14-16-yr period oscillation in the strength of the subtropical anticyclone concomitantly with fluctuations of a subtropical dipole in the SSTs. In their study, this coupling is stronger during austral summer. Using the NCAR CCSM coupled model, Wainer and Venegas (2002) found significant oscillations of a $25-30$-yr period in the SST, sea level pressure and barotropic transport fields in subtropical South Atlantic.
During the spring season, Fig. 9d reveals an increase/decrease in precipitation over most of Brazil, in a zone that extends to the South Atlantic Ocean. This band of positive values appears to be associated with an earlier SACZ onset. Negative eigenvectors can be seen over the extreme northwest South America indicating the suppression/enhancement of convection over the Amazon Basin. Negative values are also shown over southern Brazil and over the extratropical latitudes of the South Atlantic. This pattern is associated with a variability of 4-yr period. It is similar to the one containing the ENSO signal (Fig. 5d), unless for its magnitude (note that the patterns of variability vary from 
the positive to the negative phase according to their time series). A much stronger signal appeared when the influence of the tropical Pacific SSTs is removed. This suggests that the South Atlantic SST anomalies have an important impact over both the ocean and the continent during the SON months. Moreover, the enhancement of this pattern after removing the ENSO signal suggests that the warm SST anomalies in eastern Pacific counteract the effect of the South Atlantic SSTs on the South America monsoon onset.

The second mode of variability can be seen in Fig. 10. It accounts for approximately $23 \pm 3 \%$ of the total variance in DJF, $18 \pm 2 \%$ in MAM, $21 \pm 2 \% \mathrm{JJA}$ and for $17 \pm 2 \%$ in SON.

The DJF pattern (Fig. 10a) shows a dipole across the southeast Brazilian coast. This may be related to the zonal displacement of the SACZ band along the Brazilian coastal area. In the positive phase of the mode, precipitation is enhanced over the Southeast Brazil, while in its negative phase rainfall shifts northeastwards. This mode of variability agrees with Barreiro et al. (2002). After the subtraction of the ENSO-related signal, the second mode appears to be more localized; with an increase in the explained variance and an associated time series with higher frequencies (see Fig. 6a for comparison). Variability over northeastern Brazil almost disappears after the ENSO subtraction (Figs. 6a and 10a). Indeed, El Niño warm events tend to affect the rainfall over this region. The power spectrum analysis contains more energy in Fig. 10a than in 6a. It reveals two significant peaks with a period of 3-4 years and 2 years. Thus, we conclude that the SST anomalies in the subtropical South Atlantic modulate the position of the SACZ over its coastal branch in interannual timescales.

The austral autumn REOF mode (Fig. 10b) reveals a well defined variance over the tropical ocean extending westward to the extreme Northeast Brazilian region. Comparison between the second REOF mode with and without the ENSO signal indicates almost no changes (Figs. $6 \mathrm{~b}$ and $10 \mathrm{~b}$, respectively). This suggests that not only ENSO influences the intensity of the ITCZ band during austral autumn, but mostly the local SSTs from South Atlantic Ocean.

Figure 10c does not shown significant differences from Fig. 6c. This agrees with the very low regression field seen in Fig. 8c. Thus, the second mode of variability in JJA is a response of precipitation to local SSTs in subtropical South Atlantic associated with a 4-5-yr period.

The same can be assumed for the SON months. The second REOF mode in Fig. 10d preserves the same variability pattern to the one including the ENSO signal (Fig. 6d). It suggests an enhanced convection over the Amazon Basin and Central Brazil in its positive phase and a suppression of the convection during its negative phase. Three significant peaks are associated with this pattern: 5, 2.5 and 1.5 years.

The EOF analysis from EXP1 after removing the ENSO effect (figure not shown) reveals stronger magnitudes over the tropical South Atlantic for all seasons than those from
EXP2. This is an expected result as EXP1 also contains the atmospheric response from the tropical Atlantic Ocean.

\section{Summary and discussions}

In this study we investigate the impact of the subtropical South Atlantic SSTs with and without the ENSO influence, in two ensembles using different distribution of surface forcing. An attempt is made to reduce the internal variability and enhance the forced response due to SSTs.

The major findings of this study are described as follow.

- Generally, reproducibility is larger in the tropical Atlantic than in the extratropics, suggesting that lower latitudes are more sensible to the boundary forcing. The seasonal dependence of reproducibility showed larger values in MAM and SON and lower in DJF and JJA. The transient seasons revealed higher reproducibility over the South America continent, while the extreme seasons showed larger values over the tropical ocean.

- The SACZ region is dominated by internal variance, approximately $70 \%$ in DJF. On the other hand, the ITCZ region over the tropical Atlantic is mostly driven by changes in SSTs, which makes it more predictable than the SACZ.

- After the reconstruction of ensemble, the oceanic branch of the SACZ in DJF had its reproducibility significantly increased. This suggests that the oceanic SACZ may be more predictable than its coastal part.

- In DJF, both local and remote SSTs (i.e. South Atlantic and Pacific) play a role in modulating the intensity and the position of the coastal and oceanic SACZ. Particularly, the subtropical South Atlantic SSTs $\left(20^{\circ} \mathrm{S}-60^{\circ} \mathrm{S}\right)$ seem to influence more the position of this precipitation band over the Brazilian coastal region than the ENSO does. On the other hand, the warm events in the tropical Pacific have considerable effect on the intensity in the oceanic branch of the SACZ, especially during the MAM months. However, it should be noted that the internal variance is not negligible.

- During the MAM and JJA seasons, local SSTs (between $20^{\circ} \mathrm{S}$ and $60^{\circ} \mathrm{S}$ ) play an important role in determining the magnitude and the displacement of the ITCZ over the tropical Atlantic. Although the remote effect from Pacific Ocean can be detected in the tropical Atlantic precipitation field, the dominant SST forced signal in the ITCZ seems to come from the South Atlantic Ocean.

- In SON, high variability is located over South America, particularly over the Amazon. It may be associated with the enhancement/weakening of the convective activity over the Amazon Basin. The first mode of rainfall variability during SON revealed significant changes 
after subtracting the ENSO signal. This suggests that while the local South Atlantic SSTs appear to influence an earlier SACZ onset, the remote SST anomalies in the eastern tropical Pacific seems to counteract this effect.

As mentioned in Sect. 4, the reproducibility found here is dependent on the model and variables studied. As the estimate of the internal variability contains all the errors intrinsic of the model (such as Rossby wave propagation, surface atmosphere interactions, including with the topography, specific physical parameterizations, among other factors) it is expected that different models give distinct maps of reproducibility and hence predictability. The distribution of reproducibility in summer found in this study, though, are in agreement with findings of Barreiro et al. (2002) who reported that the SACZ is dominated by internal variance. The other seasons cannot be compared with other studies, since there are no previous works that have addressed this kind of analysis for South American rainfall.

The results presented in this paper provide strong evidence of the importance of the subtropical South Atlantic SST anomalies on the modulation of the SACZ position over the continent. It is worth noting that this study considers the oceanic influence on South America precipitation in timescales greater than one month, i.e. interannual to multidecadal. As the simulations are averaged over each month, the intraseasonal variability is not resolved by the model outputs and thus the MJO is not the focus of this work.

This study also provides evidence that the subtropical South Atlantic SSTs have the potential to impact rainfall over the tropics. While it may seem unusual that the subtropical South Atlantic SST anomalies influence the convection and position of the ITCZ, it is important to note that a subtropical heat source in the Atlantic could impact both tropical and extratropical atmospheric patterns (Huang and Shukla, 2005). Using numerical experiments, Haarsma et al. (2003) found that the South Atlantic subtropical dipole, the dominant mode of variability in the SST anomalies, do have a significant effect on the equatorial atmospheric dynamics. The authors reported a deep baroclinic response over the equatorward pole and a shallow equivalent barotropic response over the poleward pole. The diabatic heating from the SST dipole induces an anomalous vertical circulation, generating upward motion southward of the ITCZ and downward motion north of it, thus shifting the convergence zone to south. Therefore, enhanced precipitation occurs over the ascend region, southward of the ITCZ mean position, and is maintained by anomalous convergence of low level moisture. As our EXP2 includes the northern pole of the leading SST anomalies in the South Atlantic, it is very likely that the atmospheric response over the ITCZ region found in EXP2 occurs in a similar way as described in Haarsma et al. (2003). Further investigations of the mechanisms by which the tropical rainfall responds to the subtropical South Atlantic SST are underway.
A final important issue to be considered here is the fact that our analyses were based on an AGCM. Using an atmospheric and an oceanic model, Chaves and Nobre (2004) suggested a cloud/shortwave SST negative feedback between the atmosphere and the ocean during summer time at the SACZ region. These authors argue that the negative SST anomalies underlying the oceanic SACZ are a response to the atmospheric forcing. The cold SSTs, in turn, tend to damp the precipitation band. Thus, a refined understanding of these feedback mechanisms needs to be explored by using a fully coupled model, not only for DJF but also for the remaining seasons.

Acknowledgements. The authors acknowledge CNPq, FAPESP 02/01211-0 and the Inter-American Institute for Global Change Research (IAI) for a travel grant to NCAR. They are also grateful to Leila Carvalho and Pedro Dias for their magnificent comments on this work.

Topical Editor F. D'Andrea thanks one anonymous referee for her/his help in evaluating this paper.

\section{References}

Acker, T. L., Buja, L. E., Rosinski, J. M., and Truesdale, J. E.: User's guide to NCAR CCM3, NCAR Technical Note/TN421+ia, NCAR, Boulder, CO, 210 pp, 1996.

Andreoli, R. V. and Kayano, M. T.: ENSO-related rainfall anomalies in South America and associated circulation features during warm and cold Pacific Decadal Oscillation regimes, Int. J. Climatol., 25, 2071-2030, 2005.

Barreiro, M., Chang, P., and Saravanan, R.: Variability of the South Atlantic Convergence Zone simulated by an atmospheric general circulation model, J. Climate, 15, 745-763, 2002.

Barros, V., Gonzales, M., Liebmann, B., and Calvacanti, I.: Influence of the South Atlantic convergence zone and South Atlantic sea surface temperature in interannual summer rainfall variability in Southeastern South America, Theor. Appl. Climatol., 67, 123-133, 2000.

Boville, B. and Gent, P. R.: The NCAR Climate System Model, Version One, J. Climate, 11, 1115-1130, 1998.

Branković, Č., Palmer, T. N., and Ferranti, L.: Predictability of Seasonal Atmospheric Variations, J. Climate, 7(2), 217-237, 1994.

Carvalho, L. M., Jones, C., and Liebmann, B.: Extreme precipitation events in southeastern South America and large-scale convective patterns in the South Atlantic Convergence Zone, J. Climate, 15, 2377-2394, 2002.

Carvalho, L. M., Jones, C., and Liebmann, B.: The South Atlantic Convergence Zone: Intensity, Form, Persistence, and Relationships with Intraseasonal to Interannual Activity and Extreme Rainfall, J. Climate, 17, 88-108, 2004.

Casarin, D. P. and Kousky, V.: Anomalias de precipitação no Sul do Brasil e variações na circulação atmosférica, Brazilian J. Meteorol., 1, 83-90, 1986.

Cavalcanti, I. F. A.: Teleconnection patterns orographically induced in model results and from observational data in the austral winter of the Southern Hemisphere, J. Climate, 20, 1191-1206, 2000. 
Chang, P., Saravanan, R., Ji, L., and Hegerl, G. C.: The effect of local sea surface temperatures on atmospheric circulation over the tropical Atlantic sector, J. Climate, 13, 2195-2216, 2000.

Chaves, R. R. and Nobre, P.: Interactions between sea surface temperature over the South Atlantic Ocean and the South Atlantic Convergence Zone, Geophys. Res. Lett., 31, L03204, doi:10.1029/2003GL018647, 2004.

Cunningham, C. A. C. and Cavalcanti, I. F. A.: Intraseasonal modes of variability affecting the South Atlantic Convergence Zone, Int. J. Climatol., 26(9), 1165-1180, 2006.

de Souza, E. B. and Ambrizzi, T.: Modulation of the intraseasonal rainfall over tropical Brazil by the Madden-Julian oscillation, Int. J. Climatol., 26(13), 1759-1776, 2006.

Diaz, A. F., Studzinski, C. D., and Mechoso, C. R.: Relationships between precipitation anomalies in Uruguay and southern Brazil and sea surface temperature in the Pacific and Atlantic oceans, J. Climate, 11, 251-271, 1998.

Drumond, A. R. M. and Ambrizzi, T.: The role of SST on the South America atmospheric circulation during January, February and March 2001, Clim. Dynam., 24, 781-791, 2005.

Figueroa, S. N., Satyamurty, P., and Dias, P. L. S.: Simulations of the summer circulation over South American region with an Eta coordinate model, J. Atmos. Sci., 52, 1573-1584, 1995.

Gandu, A. W. and Geisler, J. E.: A Primitive Equations Model Study of the Effect of Topography on the Summer Circulation over Tropical South America, J. Atmos. Sci., 48(16), 1822-1836, 1991.

Garreaud, R. and Battisti, D. S.: Interannual and interdecadal (ENSO-like) variability in the Southern Hemisphere tropospheric circulation, J. Climate, 12, 2113-2123, 1999.

Grimm, A. M.: The El Niño impact on the summer monsoon in Brazil: Regional processes versus remote influences, J. Climate, 16, 263-280, 2003.

Grimm, A. M., Barros, V. R., and Doyle, M. E.: Climate variability in Southern South America associated with El Niño and La Niña events, J. Climate, 1, 35-58, 2000.

Grimm, A. M. and da Silva Dias, P. L.: Analysis of tropicalextratropical interactions with influence functions of a barotropic model, J. Atmos. Sci., 52, 3538-3555, 1995.

Haarsma, R. J., Campos, E. J. D., and Molteni, F.: Atmospheric response to South Atlantic SST dipole, Geophys. Res. Lett., 30(16), 1864, doi:10.1029/2003GL017829, 2003.

Hack, J. J., Kiehl, J. T., and Hurrell, J.: The hydrologic and thermodynamic characteristics of the NCAR CCM3, J. Climate, 11, 1179-1206, 1998.

Hastenrath, S.: Climate Dynamics of the Tropics, Kluwer Academic Publishers, University of Wisconsin, Madison, USA, 488 pp., 1991.

Hastenrath, S. and Heller, L.: Dynamics of climatic hazards in northeast Brazil, Q. J. Roy. Meteorol. Soc., 103, 77-92, 1977.

Herdies, D. L., da Silva, A., Dias, M. A. S., and Nieto-Ferreira, R.: Moisture budget of the bimodal pattern of the summer circulation over South America, J. Geophys. Res., 107, 8075-8088, 2002.

Kalnay, E., Mo, K. C., and Paegle, J.: Large amplitude, short-scale stationary Rossby waves in the Southern Hemisphere: Observations and mechanistic experiments to determine their origin, J. Atmos. Sci., 43, 252-275, 1986.

Karoly, D. J.: Southern Hemisphere circulation features associated with El Niño-Southern Oscillation events, J. Climate, 2, 1239-
$1251,1989$.

Kiehl, J. T., Hack, J. J., Bonan, G., Boville, B. A., Williamson, D., and Rasch, P.: The National Center for Atmospheric Research Community Climate Model: CCM3, J. Climate, 11, 1131-1149, 1998.

Kodama, Y. M.: Large-scale common features of subtropical precipitation zones (the Baiu frontal zone, the SPCZ and SACZ). Part I: Characteristics of subtropical frontal zones, J. Meteor. Soc. Japan, 70, 813-836, 1992.

Kodama, Y. M.: Large-scale common features of subtropical precipitation zones (the Baiu frontal zone, the SPCZ and SACZ). Part II: Conditions of the circulations for generating the STCZs, J. Meteor. Soc. Japan, 71, 581-610, 1993.

Kousky, V.: Frontal influences on Northeast Brazil, Mon. Weather Rev., 107, 1140-1153, 1979.

Kousky, V.: Diurnal rainfall variation in Northeast Brazil, Mon. Weather Rev., 108, 488-498, 1980.

Kousky, V. E. and Ferreira, N. J.: Interdiurnal surface pressure variations in Brazil: Their spatial distributions, origins and effects, Mon. Weather Rev., 109, 1999-2008, 1981.

Kousky, V. E., Kayano, M. T., and Cavalcanti, I. F. A.: A review of the Southern Oscillation and their relationship to precipitation anomalies with emphasis on the South American region, Tellus, Ser. A, 34A, 490-504, 1984.

Lau, N.-C.: Interactions between global SST anomalies and the midlatitude atmospheric circulation, B. Am. Meteor. Soc., 78, 21-33, 1997.

Lau, N.-C. and Nath, M. J.: A modeling study of the relative roles of tropical and extratropical SST anomalies in the variability of the global atmosphere-ocean system, J. Climate, 7, 1184-1207, 1994.

Lenters, J. D. and Cook, K. H.: Simulation and Diagnosis of the Regional Summertime Precipitation Climatology of South America, J. Climate, 8(12), 2988-3005, 1995.

Lenters, J. D. and Cook, K. H.: Summertime Precipitation Variability over South America: Role of the Large-Scale Circulation, Mon. Weather Rev., 127(3), 409-431, 1999.

Liebmann, B., Kiladis, G. N., Marengo, J. A., Ambrizzi, T., and Glick, J. D.: Submonthly Convective Variability over South America and the South Atlantic Convergence Zone, J. Climate, 12(7), 1877-1891, 1999.

Liebmann, B., Vera, C. S., Carvalho, L. M. V., Barros, V. R., Baez, J., Bidegain, M., Camilloni, I. A., Hoerling, M. P., and Allured, D.: An Observed Trend in Central South American Precipitation, J. Climate, 17(22), 4357-4367, 2004.

Madden, R. A. and Julian, P. R.: Observations of the 40-50-day tropical oscillation - a review, Mon. Weather Rev., 122(5), 814837, 1994.

Marengo, J., Douglas, M., and Dias, P. S.: The South American low-level jet east of the Andes during the LBA-TRMM and WET AMC campaign of January-April 1999, J. Geophys. Res., 107, $1-11,2002$.

Mo, K. C.: Relationships between low-frequency variability in the Southern Hemisphere and sea surface temperature anomalies, J. Climate, 13, 3599-3610, 2000.

Moura, A. and Shukla, J.: On the dynamics of droughts in Northeast Brazil: Observatons, theory, and numerical experiments with a general circulation model, J. Atmos. Sci., 38, 2653-2675, 1981.

Nobre, P. and Shukla, J.: Variations of sea surface temperature, 
wind stress, and rainfall over the tropical Atlantic and South America, J. Climate, 9, 2464-2479, 1996.

Nogués-Paegle, J. and Mo, K. C.: Alternating wet and dry conditions over South America during summer, Mon. Weather Rev., 125, 279-291, 1997.

North, G. R., Bell, T. L., Cahalan, R. F., and Moeng, F. M.: Sampling errors in the estimation of empirical orthogonal function, Mon. Weather Rev., 110, 699-706, 1982.

Paegle, J. N., Byerle, L. A., and Mo, K. C.: Intraseasonal Modulation of South American Summer Precipitation, Mon. Weather Rev., 128(3), 837-850, 2000.

Rayner, N. A., Parker, D. E., Horton, B. E., Folland, K. C., Alexander, L. V., Rowell, D. P., Kent, E. C., and Kaplan, A.: Global analyses of SST, sea ice and night marine air temperature since the late nineteenth century, J. Geophys. Res., 108(D14), 4407, doi:10.1029/2002JD002670, 2003.

Paegle, J. N. and Mo, K. C.: Linkages between Summer Rainfall Variability over South America and Sea Surface Temperature Anomalies, J. Climate, 15(12), 1389-1407, 2002.

Pezza, A. B. and Ambrizzi, T.: Variability of Southern Hemisphere cyclone and anticyclone behavior: Further analysis, J. Climate, 16, 1075-1083, 2003.

Pezzi, L. and Cavalcanti, I. F. A.: The relative importance of ENSO and tropical Atlantic sea surface temperature anomalies for seasonal precipitation over South America: a numerical study, Clim. Dynam., 17, 205-212, 2001.

Robertson, A. W. and Mechoso, C. R.: Interannual and interdecadal variability of the South Atlantic Convergence Zone, Mon. Weather Rev., 11, 2947-2957, 2000.

Robertson, A. W., Farrara, J. D., and Mechoso, C. R.: Simulations of the atmospheric response to South Atlantic sea surface temperature anomalies, J. Climate, 16, 2540-2551, 2003.

Rocha, A. M. G. C. and Gandu, A. W.: South Atlantic Convergence Zone, Climanálise, 16-10 year Special Edition, CPTEC-INPE, 140-142, São José dos Campos, São Paulo, Brazil, 1996.

Ropelewski, C. F. and Halpert, M. S.: Global and regional scale precipitation patterns associated with the El Niño/Southern Oscillation, Mon. Weather Rev., 115, 1606-1626, 1987.
Ropelewski, C. F. and Halpert, M. S.: Precipitation patterns associated with the high index phase of the Southern Oscillation, J. Climate, 2, 268-284, 1989.

Saravanan, R.: Atmospheric low-frequency variability and its relationship to midlatitude SST variability: Studies using the NCAR Climate System Model, J. Climate, 11, 1386-1404, 1998.

Saravanan, R. and Chang, P.: Interaction between Tropical Atlantic variability and El-Niño-Southern Oscillation, J. Climate, 13, 2177-2193, 2000.

Satyamurty, P. and Rao, V. B.: South Atlantic Convergence Zone, Climanálise, 3, 31-35, 1988.

Servain, J.: Simple climatic indices for the tropical Atlantic Ocean and some applications, J. Geophys. Res., 96, 15 137-15 146, 1991.

Shukla, J.: Predictability of short-term climate variations. Prediction of Interannual Climate Variations, edited by: Shukla, J., NATO ASI Series I, Global Environ. Change, 6, 217-232, 1993.

Taschetto, A. S. and Wainer, I.: Reproducibility of South America Precipitation in CCM3, J. Climate, 21(12), 2835-2851, 2008.

Taschetto, A. S. and England, M. H.: Estimating ensemble size requirements of AGCM simulations, Meteor. Atmos. Phys., 100(14), 23-36, doi:10.1007/s00703-008-0293-8, 2008.

Trenberth, K. E.: Storm tracks in the Southern Hemisphere, J. Atmos. Sci., 48, 2159-2178, 1991.

Trenberth, K. E. and Caron, J. M.: The Southern Oscillation revisited: Sea level pressures, surface temperatures and precipitation, J. Climate, 13, 4358-4365, 2000.

Xie, P. and Arkin, P. A.: Global precipitation: A 17-year monthly analysis based on gauge observations, satellite estimates, and numerical model outputs, B. Am. Meteorol. Soc., 78, 2539-2558, 1997.

Yang, X.-Q., Anderson, J. L., and Stern, W. F.: Reproducible Forced Modes in AGCM Ensemble Integrations and Potential Predictability of Atmospheric Seasonal Variations in the Extratropics, J. Climate, 11, 2942-2959, 1998. 